\title{
Article \\ Seismic Strengthening Effects of Full-Size Reinforced Concrete Frame Retrofitted with Novel Concrete-Filled Tube Modular Frame by Pseudo-Dynamic Testing
}

\author{
Jin-Seon Kim ${ }^{1}$, Ju-Seong Jung ${ }^{2}$ (), Dong-Keun Jung ${ }^{3}$, Eui-Yong Kim ${ }^{4}$ and Kang-Seok Lee ${ }^{5, *(D)}$ \\ 1 Department of Architectural Engineering, Hanyang University, Seoul 04763, Korea; ppasha1007@korea.kr \\ 2 Innovative Durable Building and Infrastructure Research Center, Hanyang University, Ansan 15588, Korea; \\ jjsshm@naver.com \\ 3 Department of Smart City Engineering, Hanyang University, Ansan 15588, Korea; jdg4346@gmail.com \\ 4 ARISU Engineering Ltd., Seoul 05404, Korea; arisucon@daum.net \\ 5 Department of Architectural Engineering \& Smart City Engineering, Hanyang University, Ansan 15588, Korea \\ * Correspondence: ksleenist@hanyang.ac.kr; Tel.: +82-31-400-5186
}

check for

updates

Citation: Kim, J.-S.; Jung, J.-S.; Jung, D.-K.; Kim, E.-Y.; Lee, K.-S. Seismic Strengthening Effects of Full-Size Reinforced Concrete Frame

Retrofitted with Novel

Concrete-Filled Tube Modular Frame by Pseudo-Dynamic Testing. Appl. Sci. 2021, 11, 4898. https://doi.org/ 10.3390/app11114898

Academic Editor: Dario De Domenico

Received: 20 April 2021

Accepted: 23 May 2021

Published: 26 May 2021

Publisher's Note: MDPI stays neutral with regard to jurisdictional claims in published maps and institutional affiliations.

Copyright: (c) 2021 by the authors. Licensee MDPI, Basel, Switzerland. This article is an open access article distributed under the terms and conditions of the Creative Commons Attribution (CC BY) license (https:// creativecommons.org/licenses/by/ $4.0 /)$.

\begin{abstract}
The present study proposes a new seismic retrofitting method using a concrete-filled tube modular frame (CFT-MF) system, a novel technique to overcome and improve the limitations of existing seismic strengthening methods. This CFT-MF seismic retrofitting method makes the most of the advantages of both concrete and steel pipes, thereby significantly improving constructability and increasing integration between the existing structure and the reinforcement joints. This method falls into the category of typical seismic retrofitting methods that focus on increasing strength, in which the required amount of seismic reinforcement can be easily estimated. Therefore, the method provides an easy solution to improving the strength of existing reinforced concrete (RC) structures with non-seismic details that are prone to shear failure. In the present study, a full-size two-story test frame modeled from existing domestic RC structures with non-seismic details was subjected to pseudo-dynamic testing. As a result, the effect of the CFT-MF system, when applied to existing RC structures, was examined and verified, especially as to its seismic retrofitting performance, i.e., restoring force characteristics, stiffness reinforcement, and seismic response control. In addition, based on the pseudo-dynamic testing results, a restoring force characteristics model was proposed to implement non-linear dynamic analysis of a structure retrofitted with the CFT-MF system (i.e., the test frame). Finally, based on the proposed restoring force characteristics, non-linear dynamic analysis was conducted, and the results were compared with those obtained by the pseudo-dynamic tests. The results showed that the RC frame (building) with no retrofitting measures applied underwent shear failure at a seismic intensity of $200 \mathrm{~cm} / \mathrm{s}^{2}$, the threshold applied in seismic design in Korea. In contrast, in the frame (building) retrofitted with the CFT-MF system, only minor earthquake damage was observed, and even when the maximum seismic intensity $\left(300 \mathrm{~cm} / \mathrm{s}^{2}\right)$ that may occur in Korean was applied, small-scale damage was observed. These results confirmed the validity of the seismic retrofitting method based on the CFT-MF system developed in the present study. The non-linear dynamic analysis and the pseudo-dynamic test showed similar results, with an average deviation of $10 \%$ or less in seismic response load and displacement.
\end{abstract}

Keywords: reinforced concrete; seismic strengthening; concrete-filled tube; seismic capacity; pseudodynamic testing; non-linear dynamic analysis; strength increasing

\section{Introduction}

Concrete structures may be highly prone to early degradation and damage, especially in their most vulnerable parts, if they have been improperly designed and constructed or built with inappropriate materials or when the environmental conditions are severe. This leads to a significant degradation in their safety, durability, and functionality, thereby 
increasing the frequency and scale of natural disasters and safety accidents. In particular, safety accidents are rapidly increasing in concrete structures, and the resultant damage is also increasingly severe in scale and scope. The aging and degradation of structures and their structural performance is accelerated by the degradation of the performance and functionality of their concrete parts. This degradation process is considered to be caused by a variety of factors, as mentioned above, such as the natural aging of structures, environmental changes including climate change, quality errors in design and construction, and changes in the load condition due to extension or design change. Concrete structures can be effectively used and fully implement their functionality over the required or intended period of time only when their safety is thoroughly monitored and reviewed at all times. Further, when damage occurs or may occur, maintenance and retrofitting measures must be immediately taken to ensure safety.

The world has recently seen large-scale earthquakes caused by environmental changes, including climate change, increasingly causing significant damage to various facilities, and especially structures. In Japan, China, and Taiwan, the neighboring countries of the Korean Peninsula, earthquake-induced damage is dramatically increasing. In some ways, this implies that the Republic of Korea is not free from the danger of earthquakes, whether directly or indirectly. Notably, the 2005 Fukuoka Earthquake in Japan [1], the 2008 Sichuan Earthquake in China [2], and the 2016 Kumamoto Earthquake in Japan [3] all occurred within the Eurasian Plate to which the Korean Peninsula belongs. This is explicit evidence that large-scale earthquakes may occur in Korea.

As is well known, the 2016 Gyeongju Earthquake and the 2017 Pohang Earthquake in the country already revealed the vulnerability of facilities and structures in the region, in terms of seismic safety, to a significant extent. These accidents were a huge wake-up call to the possibility of nationwide disasters. In the 2016 Gyeongju Earthquake, not many buildings or structures were subject to severe damage, except for some column damage in buildings located near the epicenter, including schools and residential buildings. In the 2017 Pohang Earthquake, however, newly built piloti structures and multi-unit dwellings (apartment buildings), including school facilities with non-seismic details, underwent severe damage [4]. In particular, reinforced concrete (RC) columns without sufficient shear reinforcement were found to be highly vulnerable to shear failure, as shown in Figure 1, which then emerged as an urgent and important issue to be addressed in the country's seismic policy development for years to come.

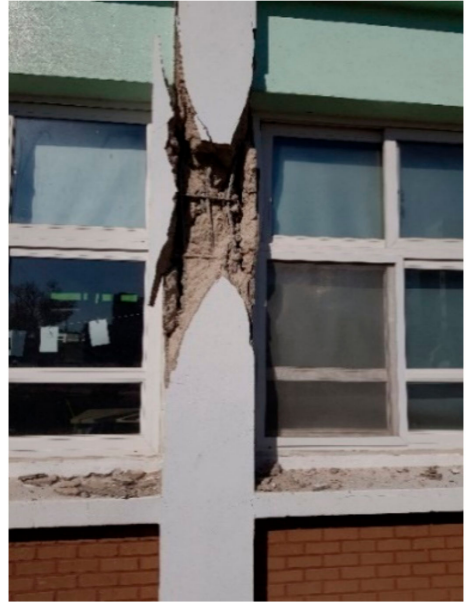

(a)

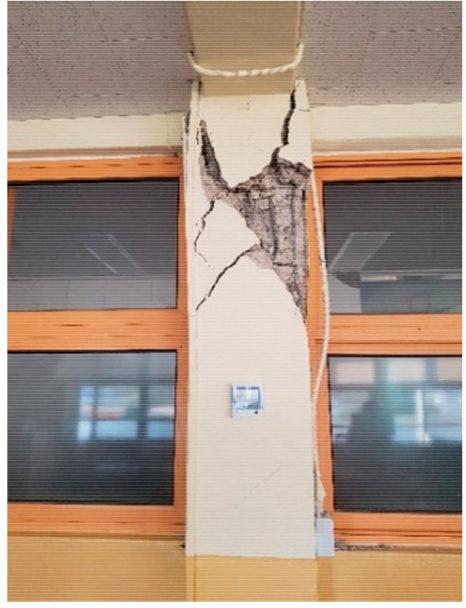

(b)

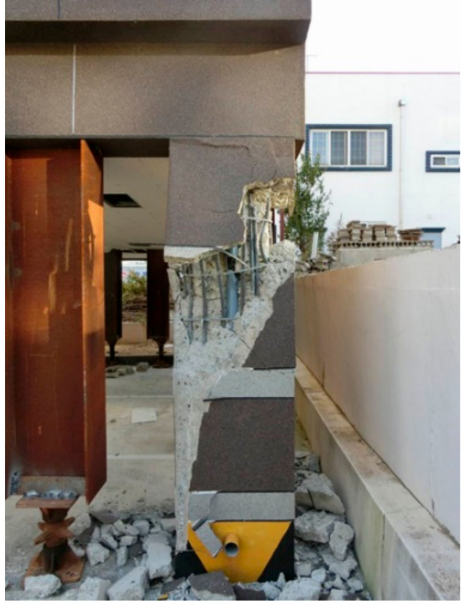

(c)

Figure 1. Damaged buildings after the 2017 Pohang Earthquake: (a) RC school building; (b) RC public building; (c) piloti building.

As demonstrated in the earthquakes in Gyeongju and Pohang, earthquakes are increasing in Korea in both frequency and intensity. Thus, to prevent structures from collapsing in the case of a large-scale earthquake, and to minimize resultant human and property 
damage, it is necessary to develop an economical and effective seismic retrofitting method to improve the seismic performance of structures that are likely to be vulnerable to earthquakes, and especially RC structures with non-seismic details, which are highly likely to undergo shear failure in their columns. Also, these seismic retrofitting measures must be conducted in an efficient and economical manner based on the expected earthquake magnitude and resultant damage.

So far, a range of methods for retrofitting the seismic performance of existing RC structures have been proposed: methods for seismic strengthening and improving deformation performance [5-19], methods for improving energy absorption capacity using vibration dampers [20-23], and the base isolation system [24].

According to Lee and Jung [25], most of the mid- and low-rise RC structures of six stories or fewer with non-seismic details are highly prone to shear failure because the spacing of transverse reinforcing bars in their columns is only about $30 \mathrm{~cm}$. Unfortunately, this was actually demonstrated in the 2017 Pohang Earthquake, as shown in Figure 1. It was also reported that seismic retrofitting methods that focus solely on improving ductility capacity are less efficient, because the ultimate horizontal strength of such structures is much lower than desired. The researchers thus concluded that seismic strengthening is a more efficient retrofitting method to improve the seismic performance of those domestic mid- and low-rise RC structures with non-seismic details [26,27].

Existing seismic retrofitting methods that focus on increasing strength mainly include methods for adding infill shear walls inside the frame; methods for installing K-shape or X-shape steel braces in the frame; methods for inserting steel plate panel walls into the frame; and internal connection methods, including cross-sectional extension methods. These existing seismic retrofitting methods based on internal connection can effectively improve the strength of structures against the horizontal force being applied [28-30].

However, existing seismic retrofitting methods involving strength increase add to the weight of structures. Given the weak foundations of RC structures with non-seismic details, the application of such methods may require foundation reinforcement work to support the weight increase. Furthermore, these methods do not allow for enough workspace during the retrofitting process. In particular, methods for installing walls with seismic design and using steel braces, among the most widely used retrofitting methods, require additional work to be done in the structure to facilitate the transport of reinforcement materials and ensure more workspace. This means that there will be less space available for the retrofitting work itself. This limited workspace then leads to a reduction in efficiency and potentially lengthens the construction period because more effort needs to be paid to ensuring integration between the existing frame and the internal reinforcement joints, as well as construction precision [30]. Therefore, it is necessary to develop a new, internal connection-based seismic retrofitting method by strength increase, that can overcome the limitations described above, best suit the seismic structural characteristics of mid- and low-rise RC structures with non-seismic details (prone to shear failure and low ultimate strength), and ensure integration between the existing frame and the seismic reinforcement materials.

The present study proposes a new seismic retrofitting method using a concrete-filled tube modular frame (referred to as CFT-MF) system, which is a novel technique to overcome and improve the limitations of existing seismic strengthening methods. This CFT-MF seismic retrofitting method makes the most of the advantages of both concrete and steel pipes, thereby significantly improving constructability and increasing integration between the existing frame and the reinforcement joints. This method falls into the category of typical seismic retrofitting methods that focus on increasing strength, in which the required amount of seismic reinforcement can be easily estimated. Therefore, the method provides an easy solution to improving the strength of existing RC structures with non-seismic details that are prone to shear failure. Additionally, the proposed CFT-MF system doesn't require foundation reinforcement work to support the weight increase when RC structures with non-seismic details that have weak foundations are applied, as stated in the next chapter. 
In the present study, a full-scale two-story test structure modeled from existing RC structures with non-seismic details in Korea was subjected to pseudo-dynamic testing. The effects of the CFT-MF system, when applied to existing RC structures, was examined and verified, especially as to its seismic retrofitting performance, i.e., restoring force characteristics, stiffness reinforcement, and seismic response control. In addition, based on the pseudo-dynamic testing results, a restoring force characteristics model was proposed to implement non-linear dynamic analysis of structures retrofitted with the CFT-MF system (i.e., the test structure). Finally, based on the proposed restoring force characteristics, non-linear dynamic analysis was conducted, and the results were compared with those obtained by the pseudo-dynamic tests.

\section{Overview of CFT-MF Seismic Retrofitting Method}

Figure 2 illustrates a widely used method for connecting existing frames with steel frames, which are composed of H-beams, for seismic retrofitting. Anchor bolt holes are installed in the existing structure using a hammer drill through the anchor holes on the flange of H-beams spaced at a constant distance from one another. This way, steel frames can be installed in the existing structure. This method, however, does not allow an anchor bolt to be installed in the center of the steel frame, where its web is located. Also, the presences of the flange and web interfere with the operation of hammer drills, i.e., there is less workspace. Therefore, workers have difficulty installing anchor holes in the vertical or horizontal direction. This may lead to construction defects, causing cracks to occur in concrete parts with low ductility. Reinforcement is then less likely to achieve the desired seismic retrofitting performance achieved by integrated behavior of the seismic reinforcement materials with the existing structure. Figure 3 illustrates a seismic retrofitting method using conventional CFT columns. Compared to the method using steel frames, this method can be more efficient in improving the strength and ductility performance of existing structures, but it requires welding professionals to weld the CFT column with its connection parts so as to ensure precision construction.

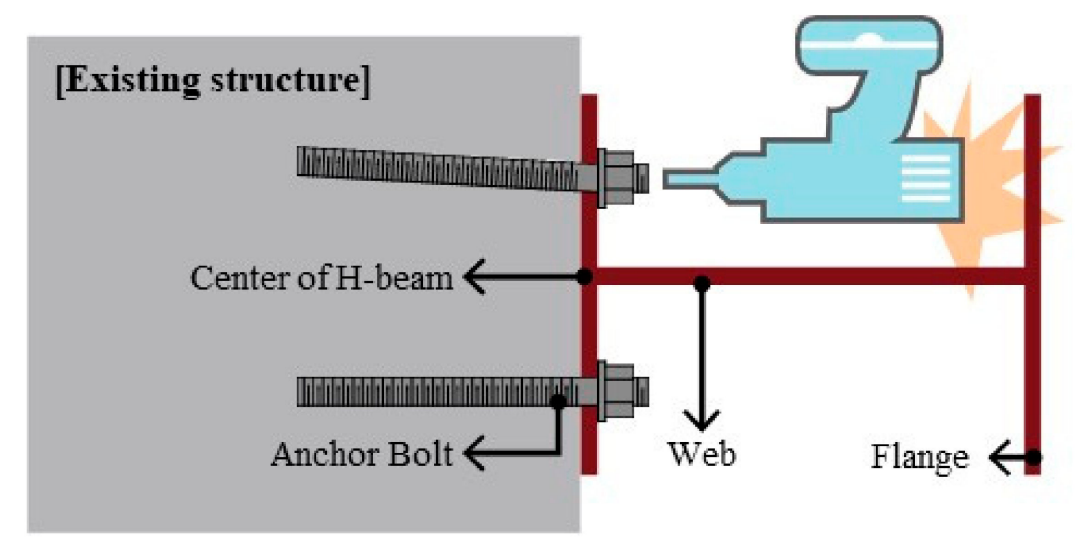

Figure 2. Conventional H-beam steel frame connection method.

Figure 4 illustrates the CFT-MF seismic retrofitting method proposed in the present study. This method was designed to overcome and improve the limitations of the steel frame connection method and the CFT column connection method described above; this method allows for sufficient workspace, ensures integration of the reinforcement connection, and improves constructability. The CFT-MF seismic retrofitting method is implemented by the following three systems: the reinforcement system, the connection system, and the filler system. The reinforcement system is composed of (a) existing structure, (b) cover plate, (c) CFT frame, and (d) connection frame, while the connection system is composed of (e) coupling bolt, and (f) chemical anchor. The filler system is composed of (g) high-performance mortar. 


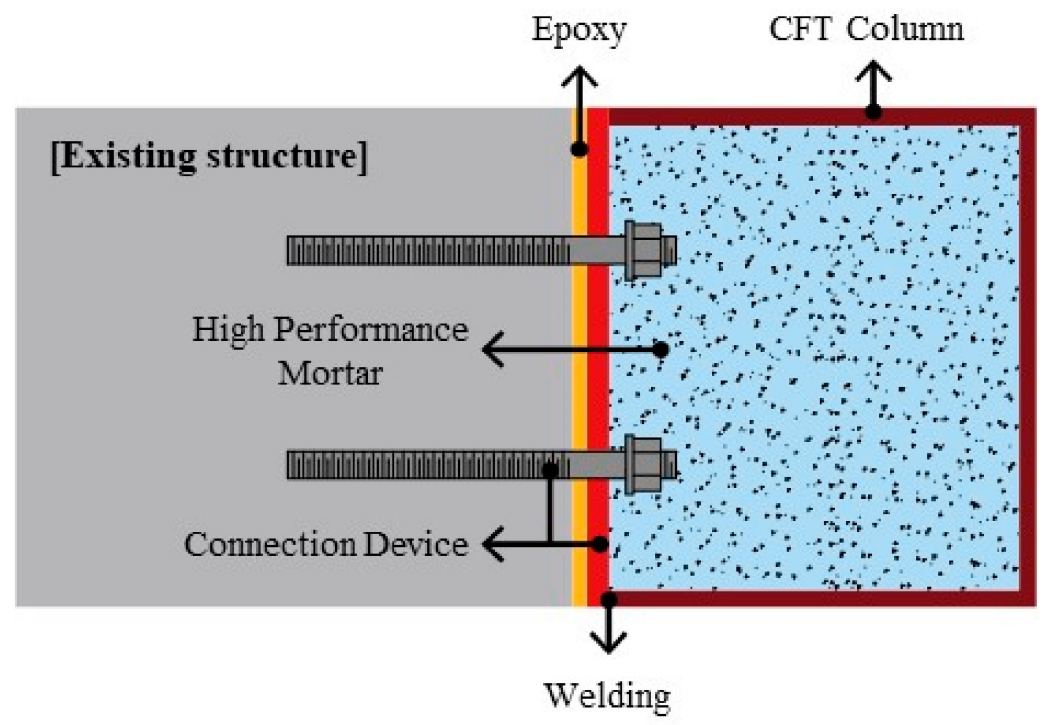

Figure 3. Conventional CFT column connection method.
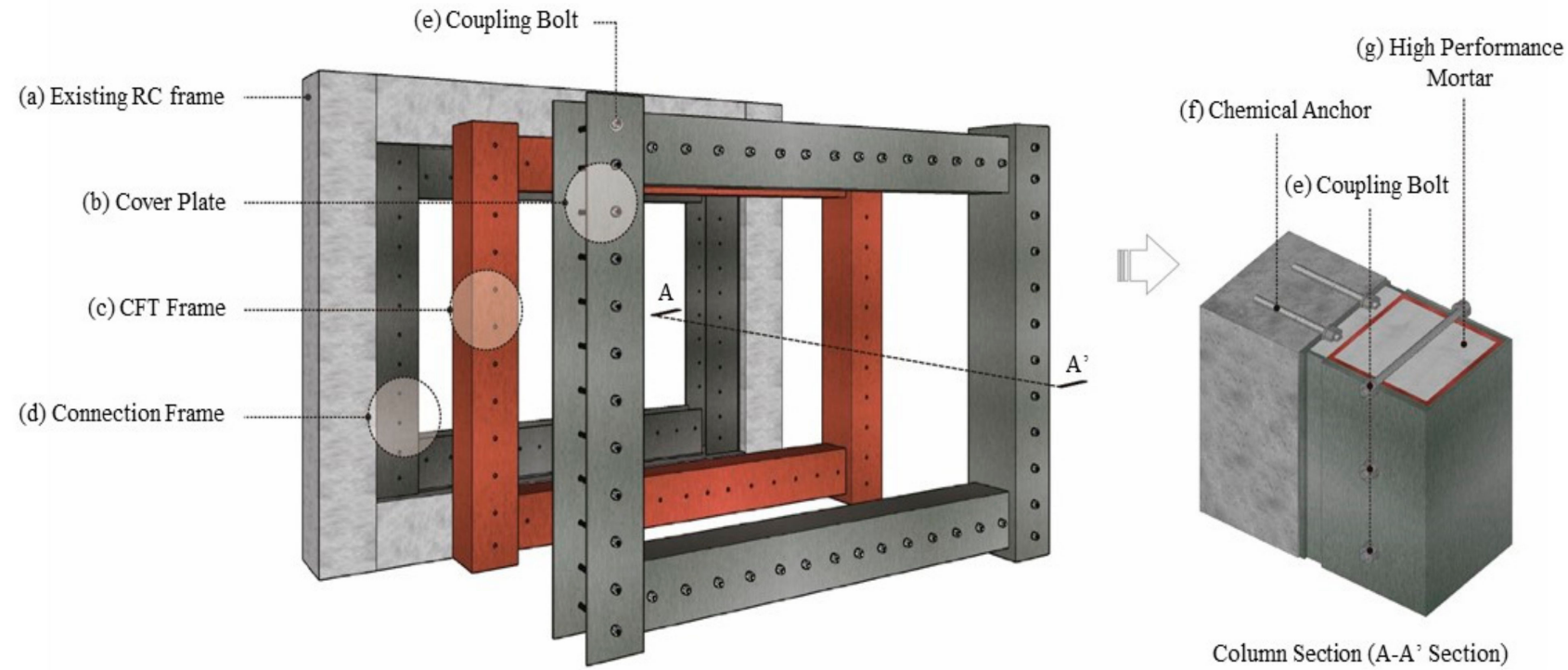

Figure 4. Detailed illustration of CFT-MF strengthening method.

Figure 5 presents the connection details of the proposed method. This method mainly involves two steps to integrate the existing structure with the reinforcement materials: connecting (a) the existing structure (RC columns and beams) with (E) the CFT connection frame using $(\mathrm{H})$ chemical anchors and $(\mathrm{G})$ epoxy resin, and then further connecting this assembly with (d) the CFT frame and (c) the cover plate using (b) coupling bolts. The detailed construction procedures, as shown in Table 1, are as follows:

(1) Bore anchor bolt holes in the existing structure (columns and beams).

(2) Install the connection device (steel plate) using anchor bolts.

(3) Install the CFT frame for seismic retrofitting.

(4) Install the cover plate (steel plate) using coupling bolts.

(5) Inject high-performance mortar and conduct finish work. 
(G) Epoxy

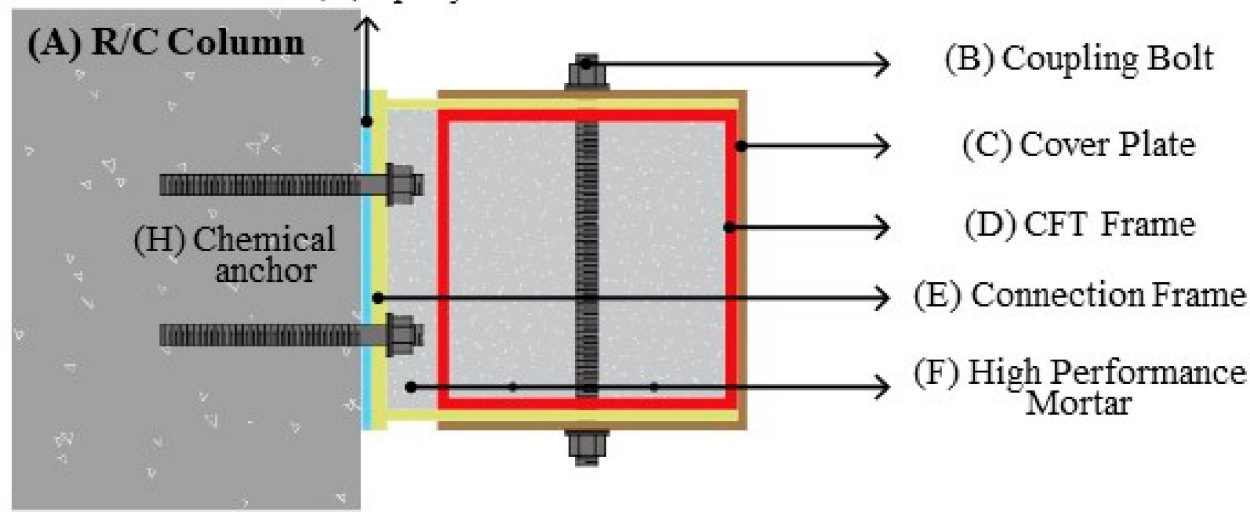

(a)

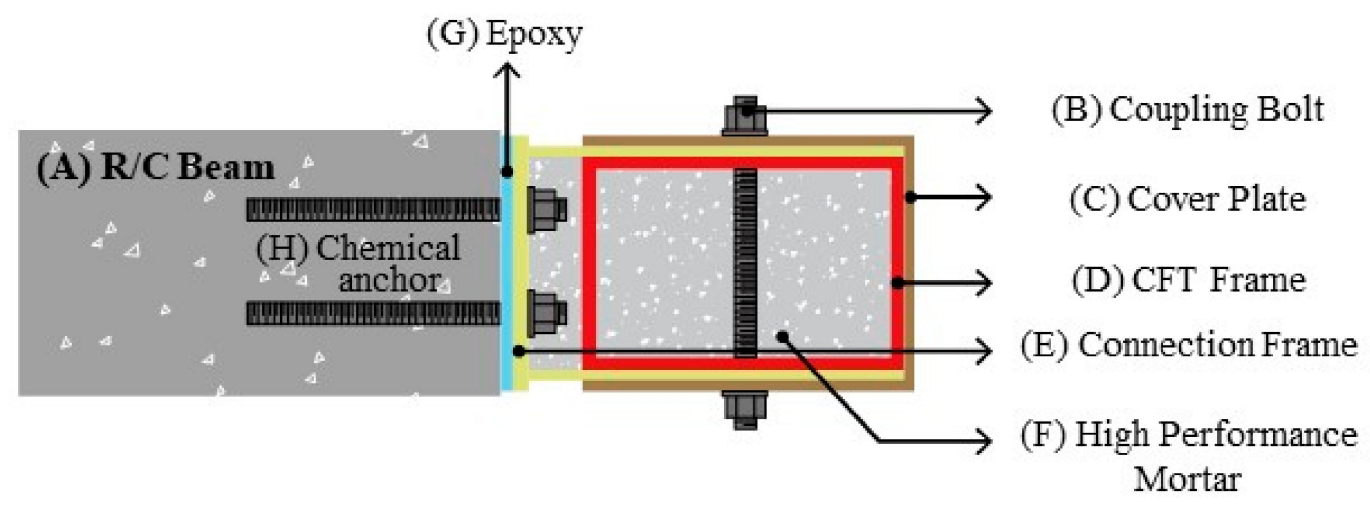

(b)

Figure 5. Connection details of CFT-MF system: (a) existing column and CFT-MF and (b) existing beam and CFT-MF.

The CFT-MF seismic retrofitting method proposed in this study is a novel technique to overcome and improve the limitations of existing seismic strengthening methods, as presented in Figures 2 and 3. The CFT-MF system makes the most of the advantages of both concrete and steel pipes, resulting in the improvement of the overall constructability and the increase of integration between the existing frame and the reinforcement joints. In addition to this, the proposed CFT-MF system does not require foundation reinforcement work to support the weight increase when RC structures with non-seismic details that have weak foundations are applied, as shown in Table 2.

Table 2 represents an example of the strengthening cost evaluation between the proposed CFT-MF system and the conventional adding infill shear wall method, which was investigated by the author. The investigated building for evaluating the strengthening cost is a three-story existing RC building with non-seismic details, as describe in the reference (27). According to Table 2, because the RC shear wall requires foundation reinforcement work, i.e., the micro-pile reinforcement, the overall construction cost of reinforcement is increased. Compared to the construction cost of the conventional shear wall system, that of the proposed CFT-MF system without foundation reinforcement is totally reduced by a cost of $15 \%$, resulting in a cost-benefit. 
Table 1. Construction procedures for CFT-MF strengthening system.

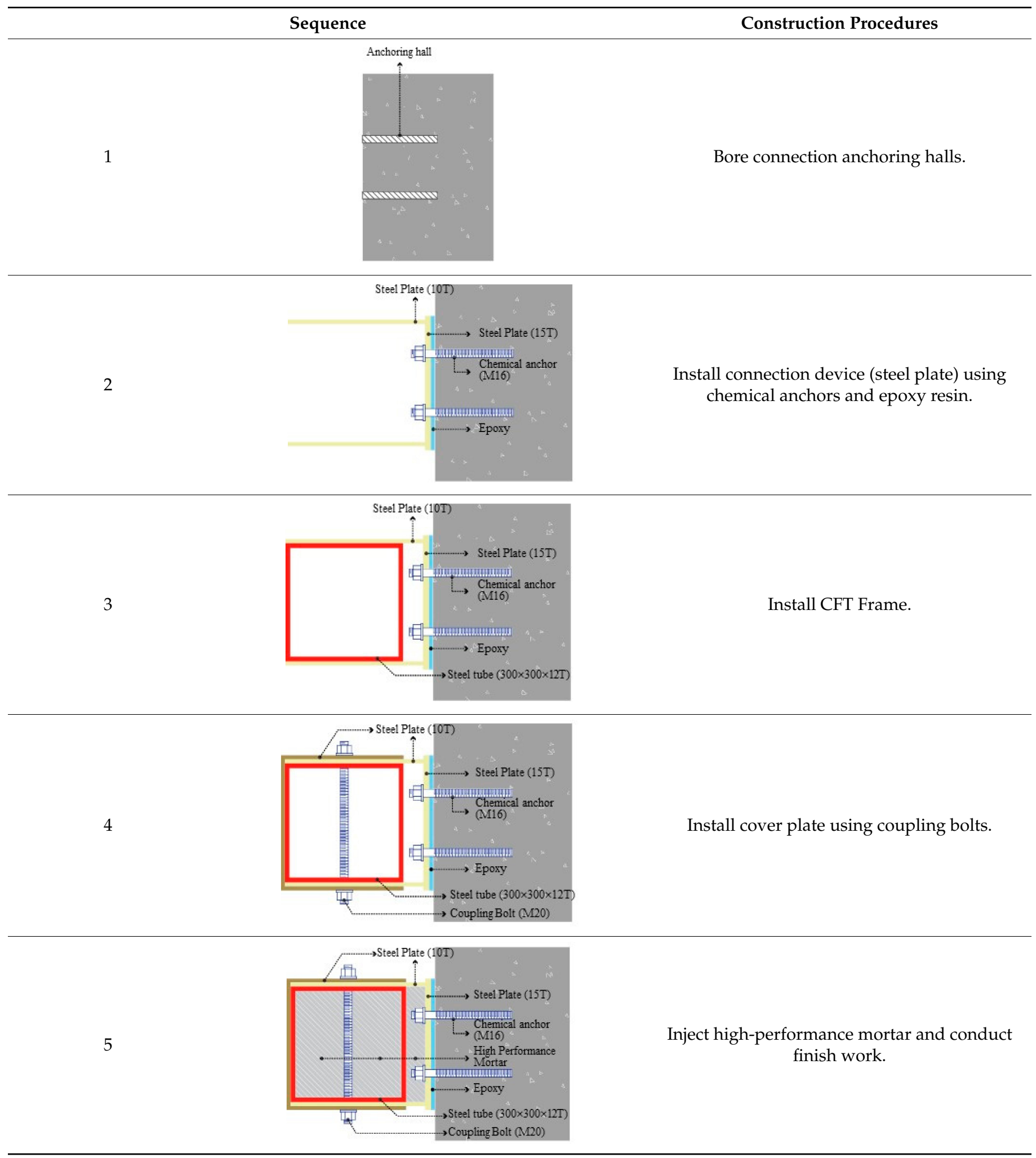


Table 2. Cost evaluation between the CFT-MF and the conventional adding infill shear wall strengthening methods.

\begin{tabular}{cccccc}
\hline $\begin{array}{c}\text { Strengthening } \\
\text { Method }\end{array}$ & Element & $\begin{array}{c}\text { Number of } \\
\text { Reinforcement }\end{array}$ & Unit Cost (USD) & Total Cost (USD) & $\begin{array}{c}\text { Cost-Benefit Ratio } \\
\text { (\%) }\end{array}$ \\
\hline \multirow{2}{*}{ RC shear wall } & Concrete shear wall & 8 & 28,351 & 385,875 \\
\cline { 2 - 5 } & Micro pile & 10 & 15,907 & 327,856 \\
\hline CFT-MF & CFT-MF & 8 & 40,982 & 15 \\
\hline
\end{tabular}

\section{Overview of Pseudo-Dynamic Testing and Result Analysis}

As shown in Figure 6 below, a full-size two-story test frame modeled from existing $\mathrm{RC}$ structures with non-seismic details in Korea was subjected to pseudo-dynamic testing using the pseudo-dynamic testing system developed in the present study. As a result, the effect of the developed CFT-MF system, when applied to existing RC structures, was examined and verified, especially as to its seismic retrofitting performance, i.e., restoring force characteristics, stiffness reinforcement, and seismic response control.

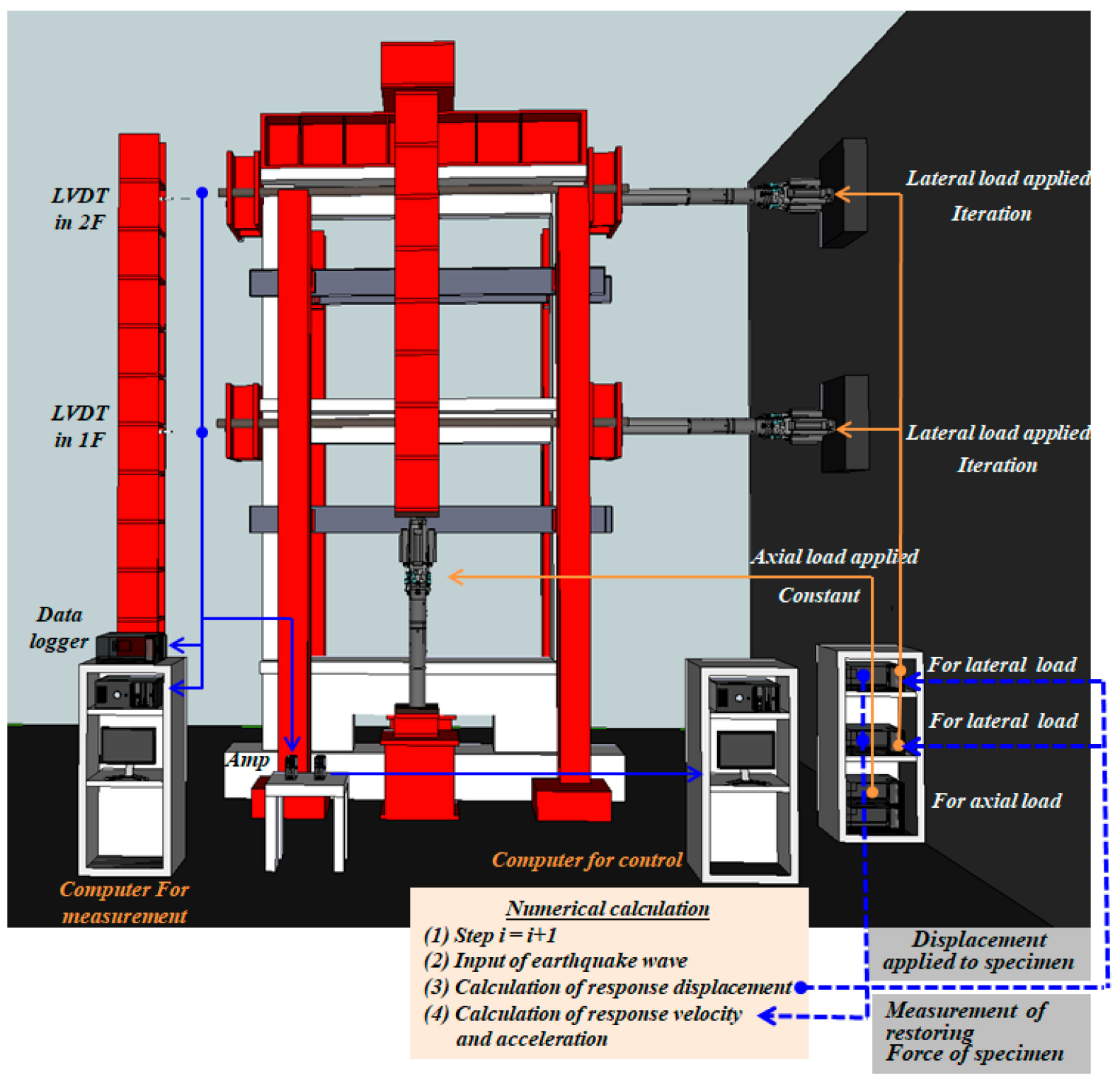

Figure 6. Illustration of the pseudo-dynamic testing system developed in the present study. 


\subsection{Pseudo-Dynamic Testing System and Test Methods}

The impact of an earthquake on a structure depends on the ground acceleration and the type, weight, and stiffness of the structure. The horizontal earthquake acceleration induces shear stress on the vertical members of the structure, which support the structure. This then subjects the structure to relative transverse motion. In general, when an earthquake occurs, many structures, even after large deformation, support themselves without structural collapse. In the process, however, they are likely to absorb some energy through nonelastic behavior.

More specifically, while the seismic load is being transmitted to a structure, some materials in the structural system reach their yield points, thereby causing localized plastic deformation to occur. The resultant large amount of earthquake input energy then starts to be absorbed by the structure through non-elastic behavior. It is, however, still very difficult or impossible to theoretically assess such non-elastic behavioral characteristics even though a wide range of relevant computing programs have been developed.

For that reason, the non-elastic seismic response of a structure has been mostly experimentally studied with various test methods, including shaking table tests, quasi-static tests, and pseudo-dynamic tests. The shaking table test method is considered to be the most effective way to assess the seismic behavior of structures, but the maximum weight and size of specimens are limited by the size and capacity of the applied shaking table. Thus, in most cases, reduced-size models are used, and this may lead to issues arising from the discrepancy between the model and the actual structure. In an attempt to overcome this limitation, quasi-static tests have been widely used to assess the non-elastic behavior of full-size structures, in which the test conditions are controlled by the displacement or load.

Meanwhile, the pseudo-dynamic test method was developed to conduct realistic experimental tests on full-scale structures subjected to earthquake ground motions [31]. This test uses an online computer and associated test instrumentation to monitor and control a structure, such that displacement thereof closely resembles the consequences of real seismic excitation. The pseudo-dynamic test is as realistic as shaking table-based testing, where discretization of the model is feasible; its advantages over shaking tables include (a) versatility, where it allows for detailed observation of the specimen during the test, (b) the ability to test full- and large-scale models, thus circumventing the problem of dynamic similitude, (c) lack of requirement for physical structures, because the method uses a numerical model, (d) greatly reduced equipment, installation, and operation costs, (e) circumventing the problems associated with the interactions of a shaking table with heavy specimens, and (f) improved actuator control and data acquisition reliability due to the relatively slow rate of loading. In principle, the test can be performed in real time; however, physical limitations of the instrumentation dictate that the test must be conducted step-by-step, i.e., pseudo-dynamically. Shaking table tests may be more appropriate in cases where strain rate effects are significant and/or in distributed parameter systems. Experimental measurements of restoring forces are performed during the test. These measured forces are then fed into the computer, together with a set of mathematical equations for inertial response characteristics, to determine the structural displacement that would occur as a consequence of a given ground acceleration. This procedure is superior to quasi-static testing because non-linear structural characteristics are based on instantaneous experimental feedback rather than hypothetical mathematical models. Pseudo-dynamic testing differs from classical computer-based structural dynamic simulations, in that the latter depend on experimentally measured restoring forces rather than on restoring forces computed using a mathematical model.

Figure 6 is a conceptual illustration of the pseudo-dynamic test system developed in the present study; this figure also shows how specimens are set and tested. As shown in Figure 6, it is a two-degree-of-freedom (TDF) system and composed of the numerical analysis unit, in which the input seismic ground motion is determined by the control computer and the loading test unit in which specimens are actually subjected to testing. The displacement response that has been calculated during the test is actually applied to 
the specimen using two hydraulic actuators that are installed in the horizontal direction. The restoring force is experimentally measured during the test, and this measurement is fed to the control computer to calculate the corresponding displacement response. Data conversion is performed by an analog-to-digital/digital-to-analog converter ([DA$16 \mathrm{~A}],[32])$, and the seismic response during pseudo-dynamic testing is calculated by the closed-loop control system.

Control computer-based numerical analysis was conducted using the Pseudo-Dynamic Testing Program [33]. Based on the restoring force of the specimen against the applied deformation measured with LVDT during the loading test, along with the input seismic acceleration and the measured response in the current step, the amount of response in the next step is calculated through numerical integration using the motion equation, as shown in Equation (1) below.

$$
M \ddot{y}(t)+C \dot{y}(t)+r(t)[=K y(t)]=-M \ddot{y}_{0}
$$

where, $M, C$, and $K$ refer to the mass, damping, and stiffness matrix of the structure, respectively. $y$ refers to the relevant displacement vector of each layer weight for the foundation. $r$ is the restoring force vector, while $\ddot{y_{0}}$ is the input ground acceleration.

The numerical integration of the motion equation was conducted using the $\alpha$-method [34], and the numerical integration algorithm for pseudo-dynamic testing is shown in Equation (2).

$$
\begin{gathered}
M a_{i+1}+(1+\alpha) C v_{i+1}-\alpha C v_{i}+(1+\alpha)-\alpha r_{i}=(1+\alpha) f_{i+1}-\alpha f_{i} \\
y_{i+1}=y_{i}+\Delta t v_{i}+\Delta t^{2}\left[\left(\frac{1}{2}-\beta\right) a_{i}+\beta a_{i+1}\right] \\
v_{i+1}=v_{i}+\Delta t\left[(1-\gamma) a_{i}+\gamma a_{i+1}\right]
\end{gathered}
$$

where, $y_{i}, v_{i}$, and $a_{i}$ refer to the joint displacement at the time corresponding to $i \Delta t$, the velocity, and the acceleration, respectively. $\Delta t$ is the time interval for integration, $r_{i}$ is the restoring force vector at the joint displacement, and $f_{i}$ is the external load vector $\left(-M \ddot{y}_{0}\right)$.

In an elastic structure, $r_{i}=K y_{i}$ applies ( $\mathrm{K}$ is the elastic stiffness matrix of the structure). $\alpha, \beta$, and $\gamma$ are parameters that control the numerical characteristics of the algorithm. The conditions $-5 \leq \alpha \leq 0, \beta=\frac{(1-\alpha)^{2}}{4}$, and $\gamma=\frac{1}{2}-\alpha$ indicate that the system is in a state of unconditional stability. In the next step, the displacement response is calculated based on the stiffness $(\mathrm{K})$, the mass $(\mathrm{M})$, and the coefficient of damping proportional to stiffness

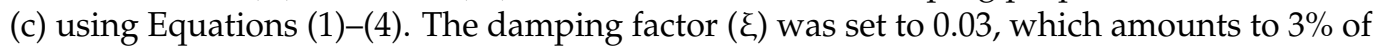
the critical damping.

As shown in Figure 6, horizontal seismic response deformation is applied to the specimen using two 2000-kN hydraulic MTS actuators on the first and second floors. The horizontal displacement used to calculate the displacement response is measured using a 300-mm linear variable differential transformer (LVDT) installed on each floor. The axial force was constantly applied to each column of the specimen using $1000-\mathrm{kN}$ oil jacks installed on each side of the specimen by properly distributing the axial load applied to the actual existing frame. Based on a study by Lee [35] on historical seismic waves, the Hachinohe wave (EW), which exhibited the largest seismic response displacement (best ductility), was selected and used to determine the seismic ground motion. The acceleration values were set to 200,300 , and $400 \mathrm{~cm} / \mathrm{s}^{2}$, and tests were then conducted using the pseudo-dynamic testing system accordingly.

\subsection{Specimen Preparation and Parameters}

A three-story RC school building frame (standard drawings of the 1980s) in Korea, as shown in Figure 7, was selected and used to verify the seismic performance of the proposed CFT-MF seismic retrofitting method. The story height was $3.3 \mathrm{~m}$, the design concrete strength was $21 \mathrm{MPa}$. Pseudo-dynamic testing was performed on a full-size two-story frame with a size of one span of the domestic RC school building. The width (b) and depth 
(d) of the cross-section of the test frame column were $350 \times 500 \mathrm{~mm}$. 8-D19 and 2-D16 were used as longitudinal reinforcing bars, while D10/300 was used as transverse reinforcing bars. The net height of the column was $2400 \mathrm{~mm}$, and the shear span-to-depth ratio was 4.8. T-shape beams were used as each floor's beams, considering the effective slab width in accordance with KDS 41 [36]. Table 3 summarizes the applied specimen parameters.

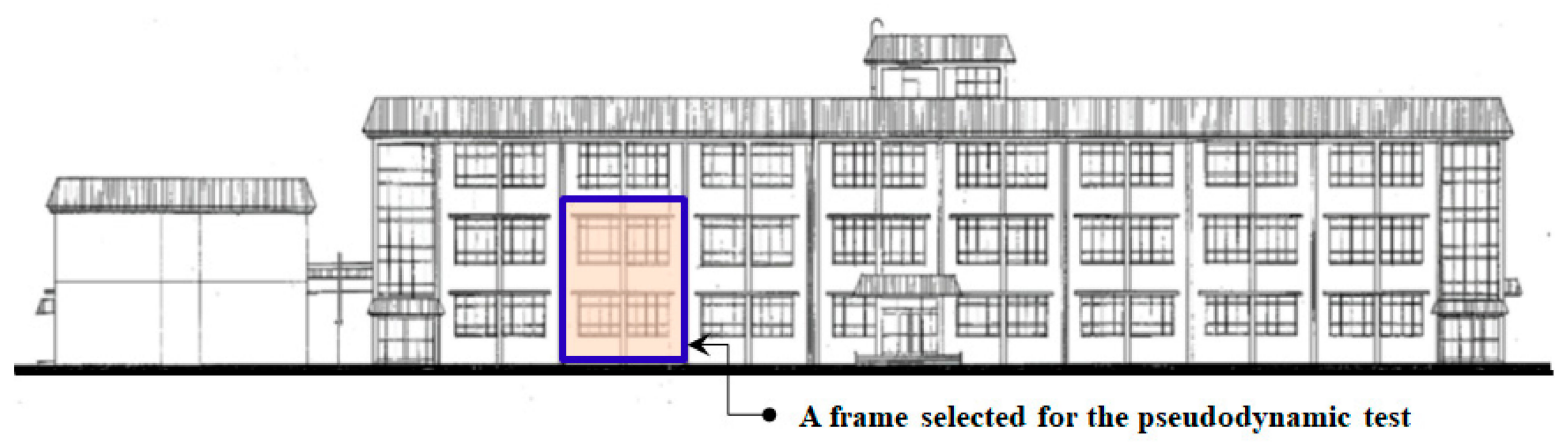

(a)

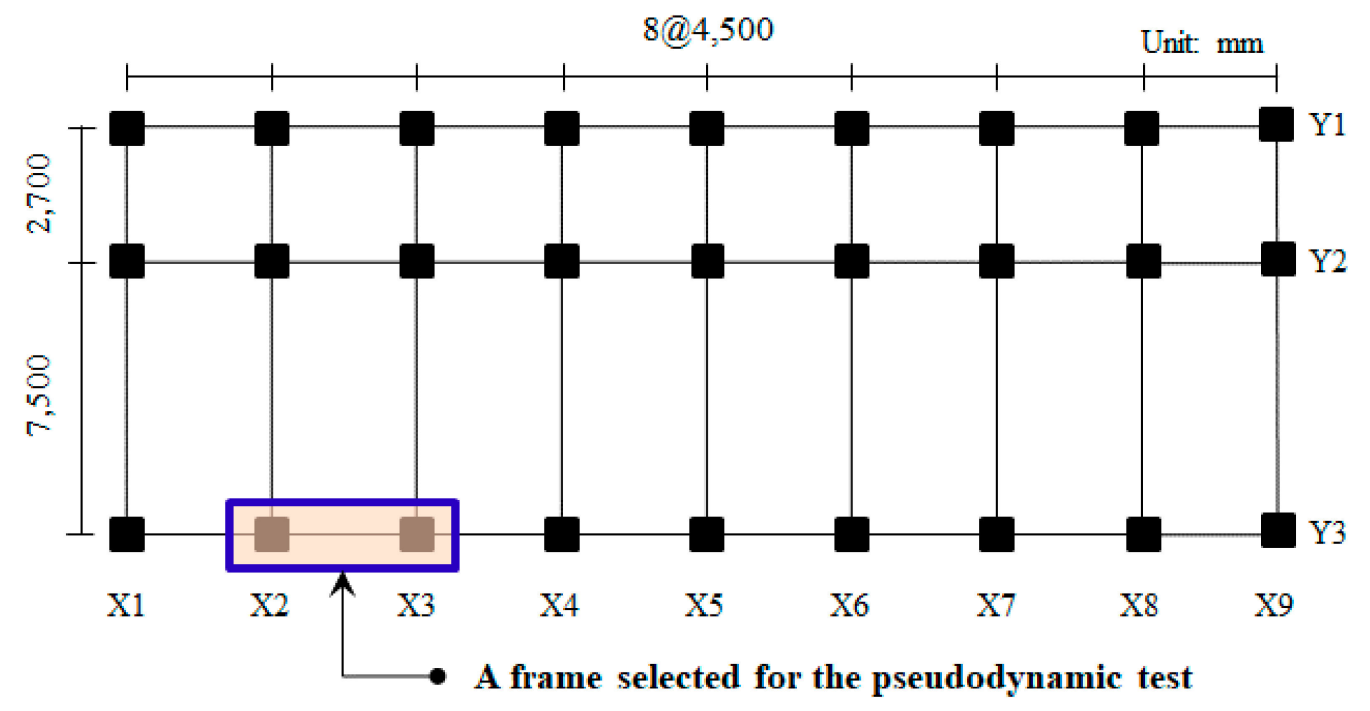

(b)

Figure 7. Shape of target building and target frame selected for pseudo-dynamic testing (a) front view and (b) top view.

Table 3. Pseudo-dynamic testing specimens and applied parameters.

\begin{tabular}{cccc}
\hline Specimen Name & Test Method & Reinforcing Method & $\begin{array}{c}\text { Input Seismic Wave } \\
\text { Intensity (cm/s } \mathbf{~})\end{array}$ \\
\hline PD-FR & Pseudo-dynamic testing & Control bare frame & 200 \\
\hline PD-CFT-MF & Pseudo-dynamic testing & CFT-MF seismic system & $200 / 300 / 400$ \\
\hline
\end{tabular}

Figure 8 shows the bar arrangement details of the existing frame with no reinforcement applied (PD-FR specimen, control bare frame for pseudo-dynamic testing), along with an image of the corresponding specimen. Figure 9 presents the bar arrangement details of the frame retrofitted with the CFT-MF system (PD-CFT-MF), along with an image of its specimen. For pseudo-dynamic testing, a test frame retrofitted with the CFT-MF system was prepared, along with a test frame with no reinforcement applied for comparison. These two test frames were subjected to the tests, and the results were compared. 


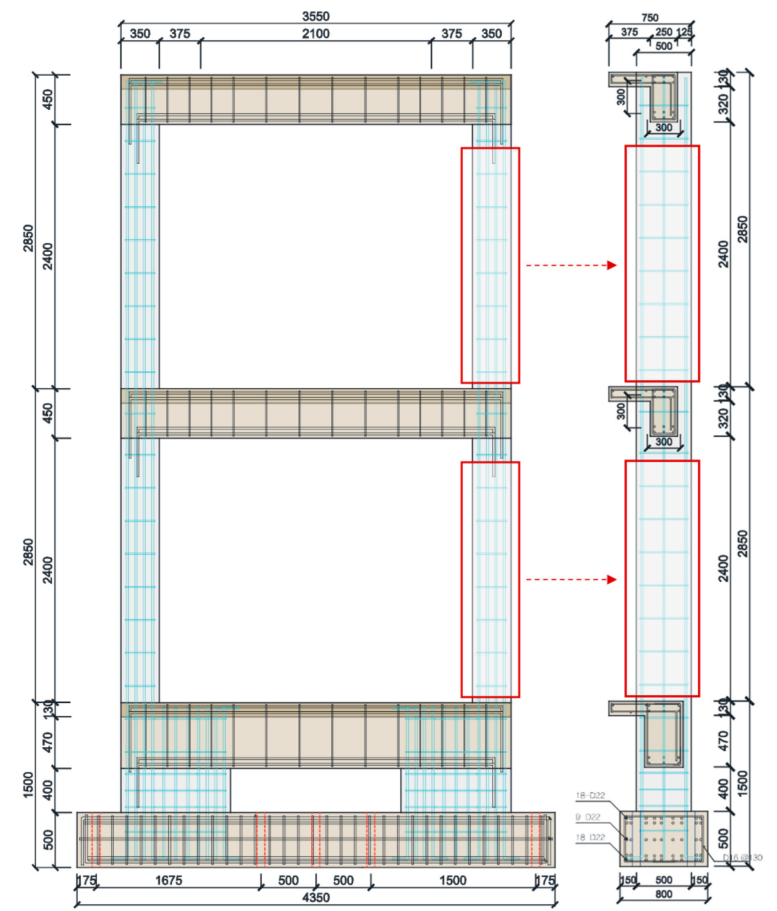

(a)

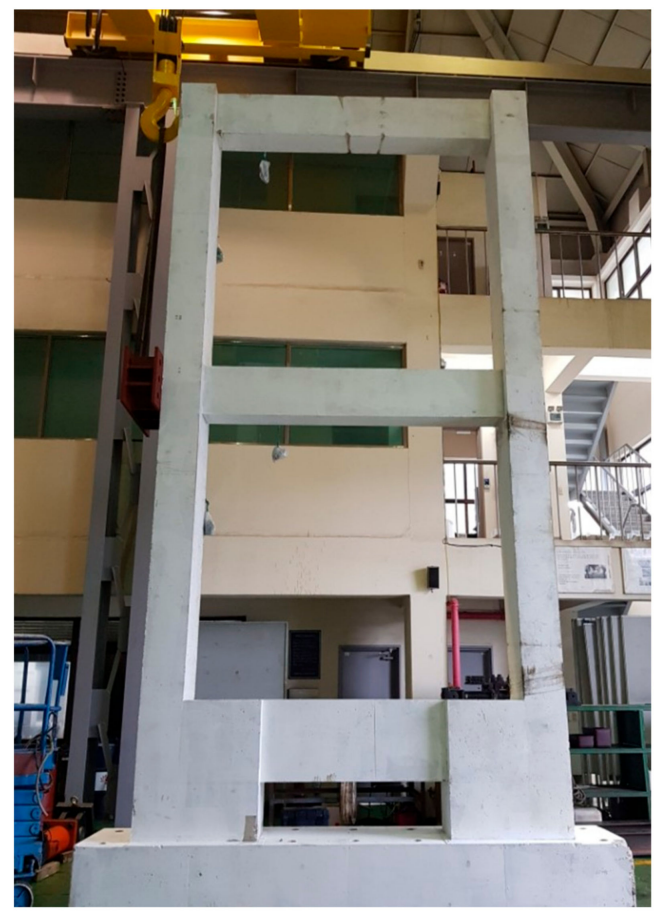

(b)

Figure 8. Bar arrangement details and image of existing frame with no reinforcement applied (PD-FR specimen, control bare frame for pseudo-dynamic testing): (a) bar arrangement details and (b) image.

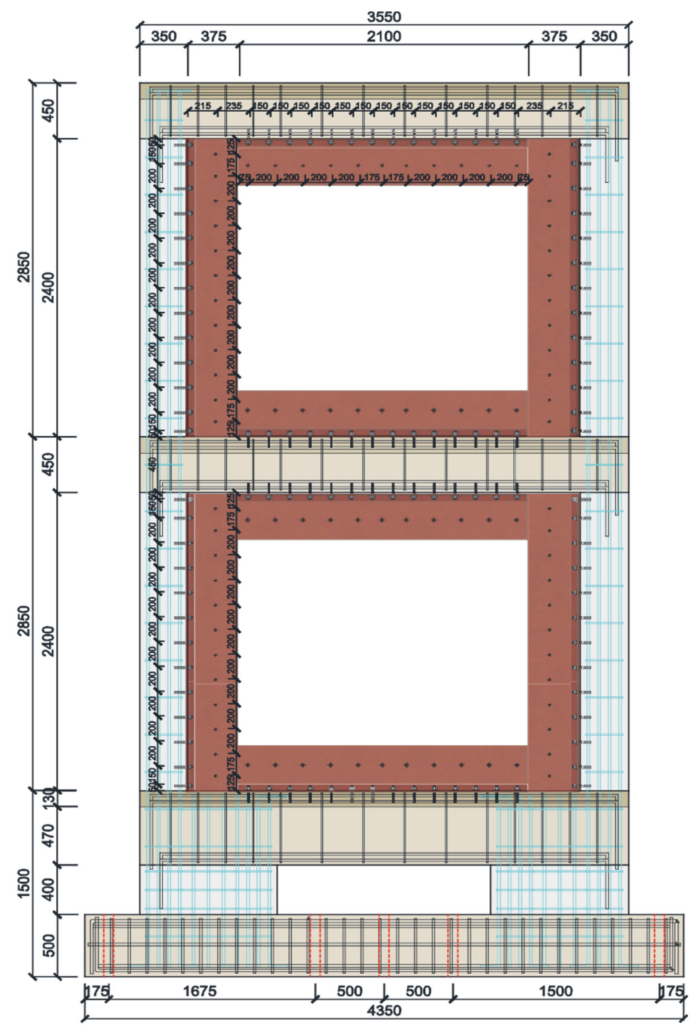

(a)

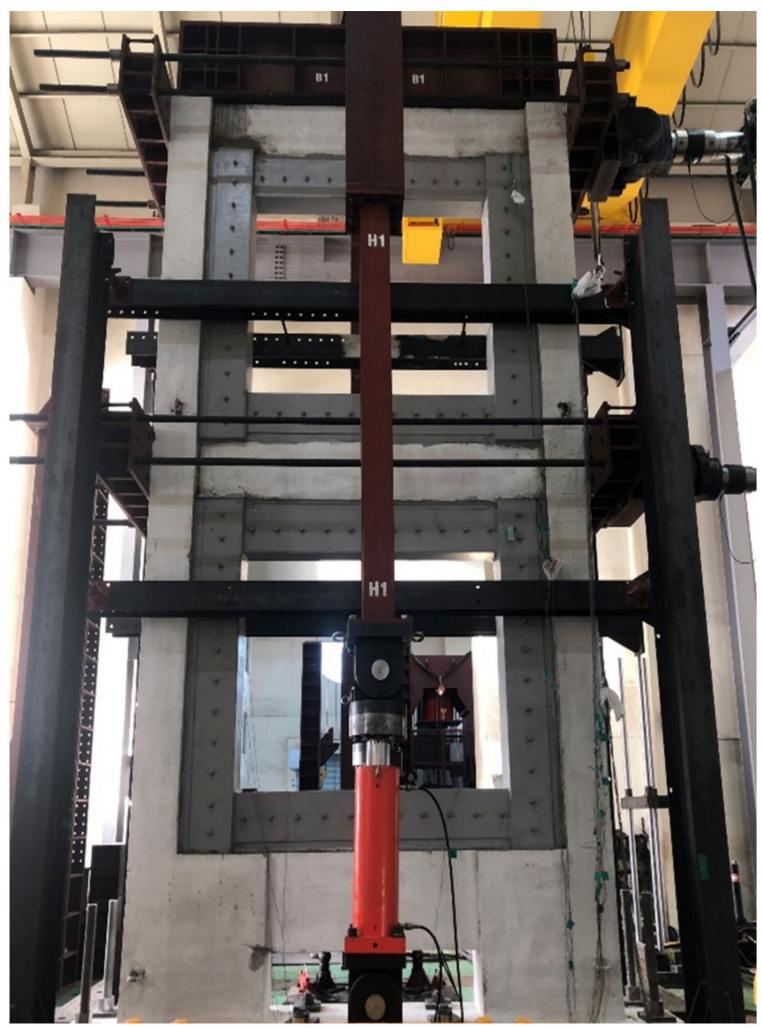

(b)

Figure 9. Bar arrangement details and image of test frame retrofitted with CFT-MF system (PD-CFT): (a) bar arrangement details and (b) image. 
According to Lee [35], the Hachinohe wave (EW) exhibited the largest seismic response displacement (ductility) among the ten historical seismic waves set for middle- and lowrise RC structures (whose strength is less than 0.5 in terms of shear coefficient). Thus, in the present study, the Hachinohe wave was selected as the input seismic ground motion for pseudo-dynamic testing. The input seismic acceleration was set by standardizing the Hachinohe wave (EW) into 200, 300, and $400 \mathrm{~cm} / \mathrm{s}^{2}$. Two-hundred and $300 \mathrm{~cm} / \mathrm{s}^{2}$ are equivalent to two-thirds of the seismic magnitude of the earthquake, with a recurrence period of 2400 years (Seismic Zone-1 and Soil Profile Type $S_{4}$ and $S_{5}$ ) defined in KDS 41 [36].

Four-hundred $\mathrm{cm} / \mathrm{s}^{2}$ was defined to examine the seismic retrofitting performance of the CFT-MF seismic retrofitting method proposed in the present study when a large-scale earthquake occurs. It is equivalent to the seismic magnitude of an earthquake with a recurrence period of 2400 years. The axial force was determined based on the axial load exerted on the actual existing frame (two columns), i.e., $1000-\mathrm{kN}$. Thus, each of the two columns was subjected to a constant axial force of $500-\mathrm{kN}$.

\subsection{Used Materials and Their Properties}

The compressive strength of the test frame concrete used in pseudo-dynamic testing was set to $21 \mathrm{MPa}$. The standard deviation was determined by averaging the compressive strength of three specimens; $97 \%$ of measured compressive strength. As a result, the average 28-day compressive strength was measured to be 21.4 MPa. SD400 (Class 1) was used as reinforcing bars. D19 and D16 were used as longitudinal reinforcing bars for column members, while D10 was used as shear reinforcing bars. Three tensile specimens of reinforcing bars were prepared in accordance with KS B 0801 [37] to examine the material properties of the reinforcing bars used for connection performance test specimens. These specimens were then subjected to tensile testing at a tensile rate of $5 \mathrm{~mm} / \mathrm{min}$ using a universal tester (U.T.M.). The results showed that the average yield and tensile strength of the reinforcing bars were $491 \mathrm{MPa}$ and $731 \mathrm{MPa}$ for both D19 and D16, respectively, and $477 \mathrm{MPa}$ and $711 \mathrm{MPa}$ for D10, respectively.

\subsection{Experimental Results and Analysis}

Both the test specimen with no reinforcement applied (PD-FR) and the test specimen retrofitted with the CFT-MF system (PD-CFT-MF) were subjected to pseudo-dynamic testing and then tested for any cracks and breakage. Further, the resultant load-displacement curves (restoring force), temporal hysteresis loops with respect to the displacement, and maximum seismic response were analyzed to determine and compare the seismic retrofitting effect of PD-FR and PD-CFT-MF.

\subsubsection{Crack and Failure Morphology}

(1) PD-FR (with no reinforcement applied)

In PD-FR with no reinforcement applied, fine initial flexural cracks started to occur at $2.34 \mathrm{~s}$ (displacement: $18 \mathrm{~mm}$ ), when the input seismic ground motion was $200 \mathrm{~cm} / \mathrm{s}^{2}$. After $2.95 \mathrm{~s}$ (displacement: $45 \mathrm{~mm}$ ), initial flexural cracks increased, and shear cracks started to occur at the lower part of the columns. After $3.17 \mathrm{~s}$, these cracks at the lower part of the column started to significantly increase in width. After $3.3 \mathrm{~s}$, severe concrete delamination started to occur, and at around $3.4 \mathrm{~s}$, where the maximum seismic response occurred, a shear collapse was observed at the lower part of the test frame, as shown in Figure 10.

This result was consistent with a previous study [38], which reported that school buildings with non-seismic details may be subject to large-scale seismic damage when an earthquake with a magnitude of $200 \mathrm{~cm} / \mathrm{s}^{2}$ occurred. This data is considered important evidence to demonstrate the necessity to apply seismic retrofitting to school buildings with non-seismic details of the 1980s. 


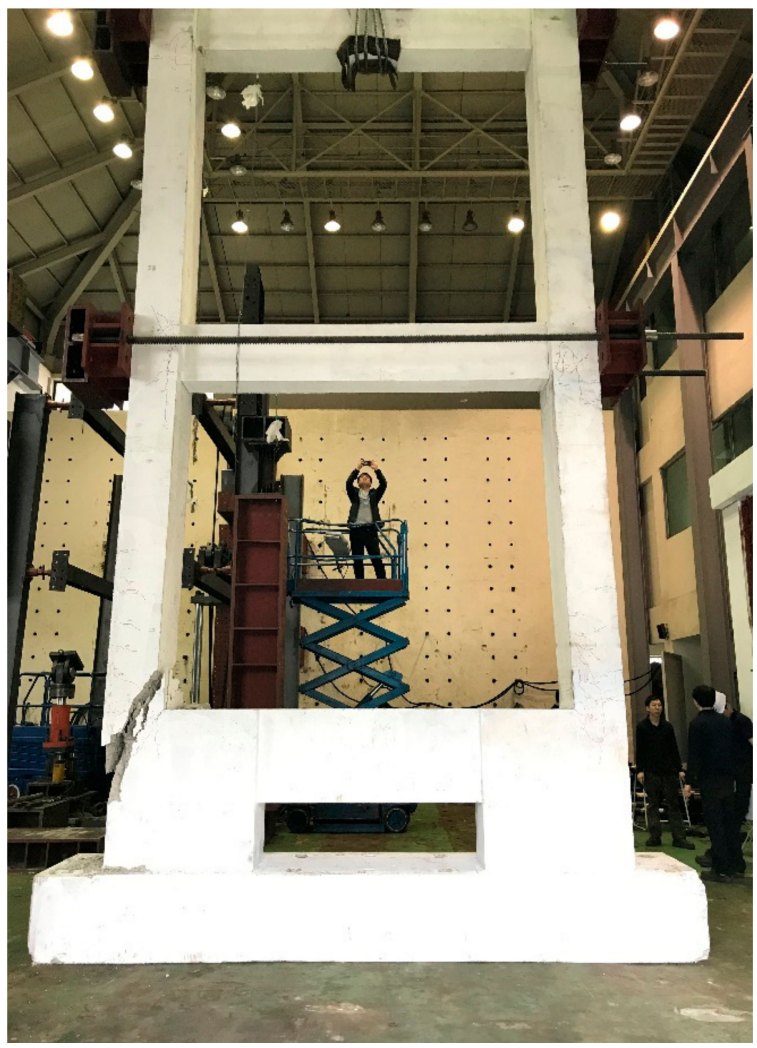

(a)

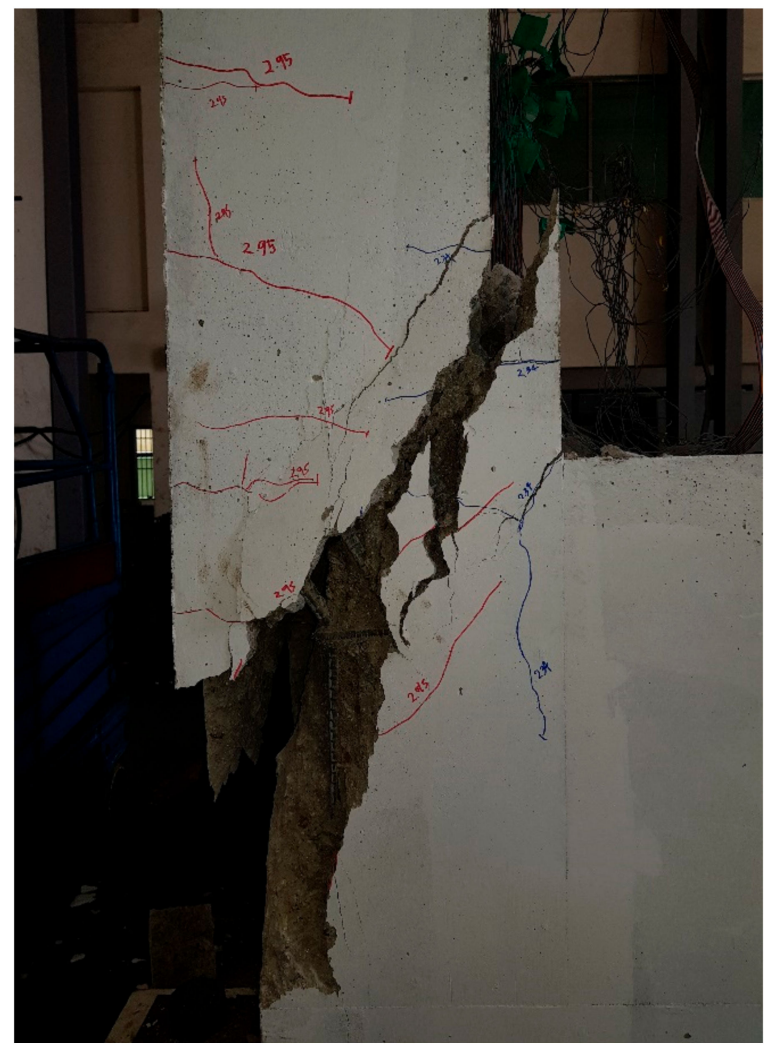

(b)

Figure 10. Cracks and ultimate failure of test frame with no reinforcement applied (PD-FR) $\left(200 \mathrm{~cm} / \mathrm{s}^{2}\right):(a)$ shear collapse at the final stage and (b) enlarged shear collapse.

(2) PD-CFT-MF (retrofitted with CFT-MF system)

PD-CFT-MF was the test frame that had been retrofitted with the CFT-MF system proposed in this present study. As shown in Figure 11, when the input seismic ground motion was set to $200 \mathrm{~cm} / \mathrm{s}^{2}$, small initial flexural cracks started to occur at the lower part of the columns at around $2.25 \mathrm{~s}$ (displacement: $5.9 \mathrm{~mm}$ ), and after $3.1 \mathrm{~s}$ (displacement: $10 \mathrm{~mm}$ ), the number of these fine initial flexural cracks increased, but the crack size was still small. After $3.59 \mathrm{~s}$ (displacement: $11.1 \mathrm{~mm}$ ), where the maximum seismic response occurred, the number of these flexural cracks continued to increase, but the crack width still remained narrow.

When the input seismic ground motion was set to $300 \mathrm{~cm} / \mathrm{s}^{2}$, shear cracks started to occur at $3.6 \mathrm{~s}$, where the maximum seismic response occurred. After then, however, these cracks increased in width, but only to a limited extent. Even after the test was complete, only small shear cracks were observed at the lower part of the columns, as shown in Figure 12, in contrast to the PD-FR specimen with no reinforcement applied, which underwent shear collapse, as shown in Figure 10.

When the input seismic ground motion was set to $400 \mathrm{~cm} / \mathrm{s}^{2}$, the magnitude of a largescale earthquake defined in accordance with KDS 41 [36], the test specimen retrofitted with the CFT-MF system, as shown in Figure 13, exhibited more severe flexural cracks and shear cracks with a larger width at $3.63 \mathrm{~s}$ (displacement: $40.61 \mathrm{~mm}$ ), where the maximum seismic response occurred, compared to when the input seismic ground motion was $300 \mathrm{~cm} / \mathrm{s}^{2}$. However, the crack size was limited to $1.0 \mathrm{~mm}$ or less. In short, PD-CFT, the test frame modeled from RC school buildings with non-seismic details but retrofitted with the CFTMF seismic retrofitting method, was subject to medium-sized cracks at a seismic ground motion of $400 \mathrm{~cm} / \mathrm{s}^{2}$. 


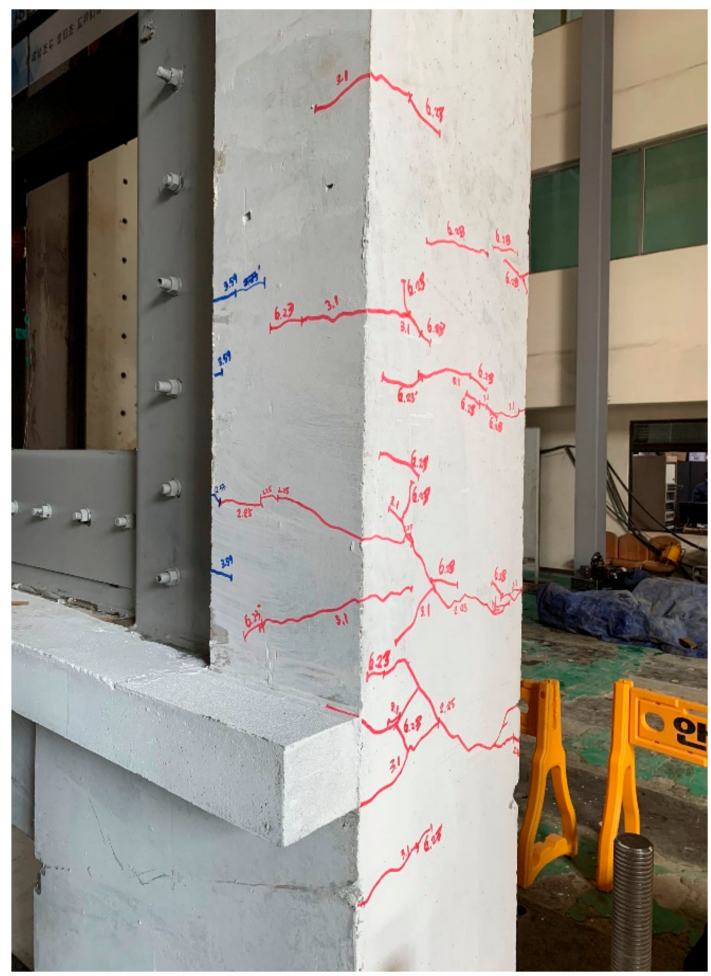

(a)

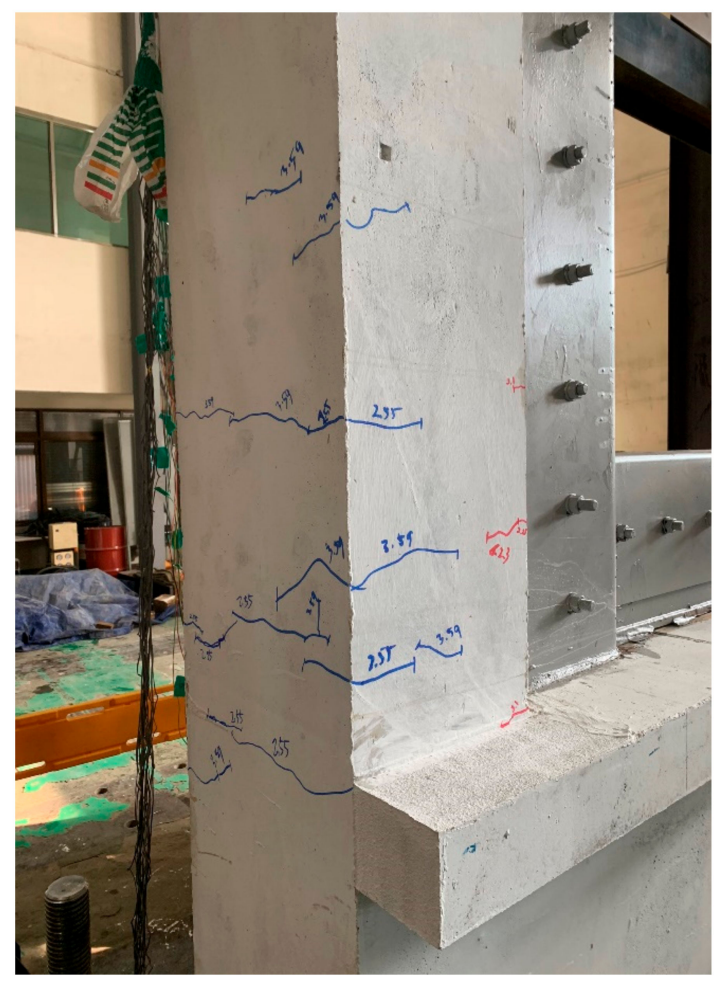

(b)

Figure 11. Cracks and ultimate state of test frame retrofitted with CFT-MF system (PD-CFT) $\left(200 \mathrm{~cm} / \mathrm{s}^{2}\right):($ a) flexural cracks at around $2.25 \mathrm{~s}$ and (b) flexural cracks at around $3.1 \mathrm{~s}$.

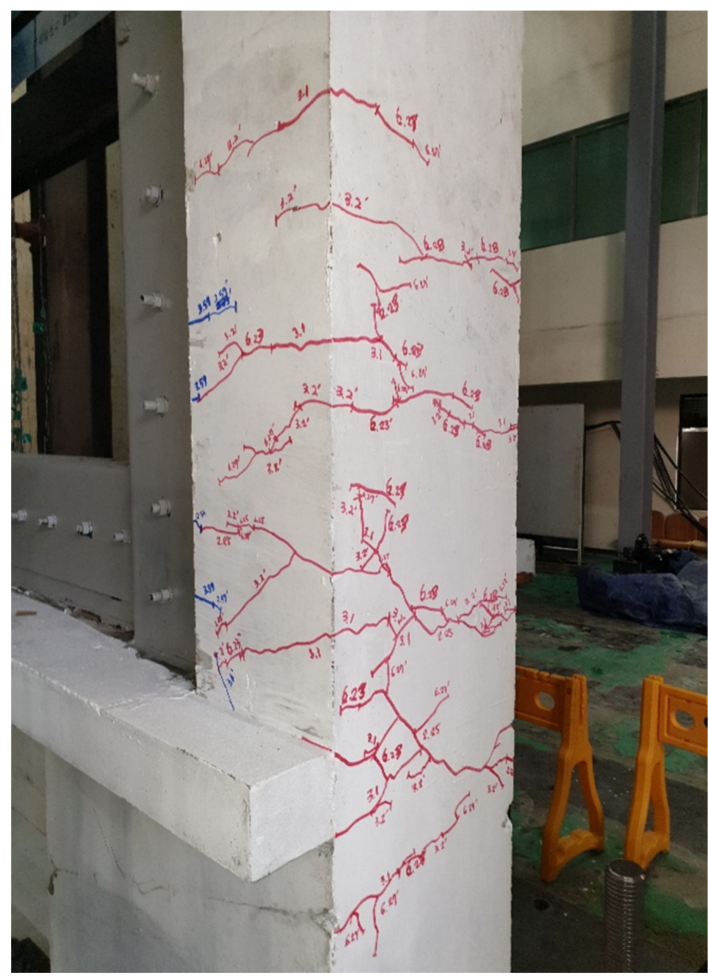

(a)

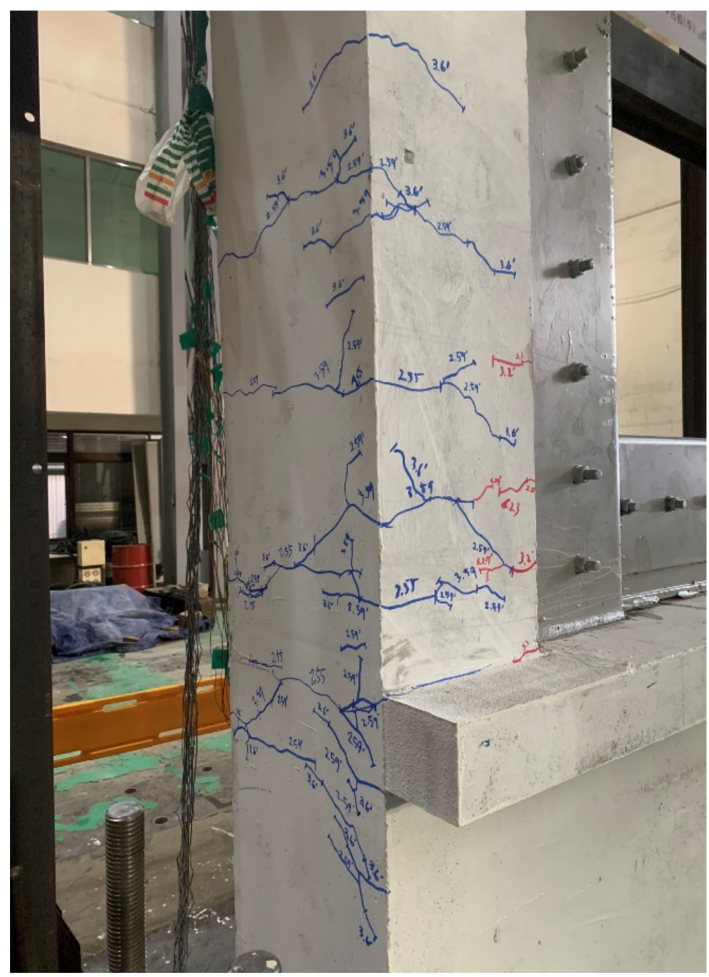

(b)

Figure 12. Cracks and ultimate state of test frame retrofitted with CFT-MF system (PD-CFT) $\left(300 \mathrm{~cm} / \mathrm{s}^{2}\right)$ : (a) small shear cracks of the right column and (b) small shear cracks of the left column at the final stage. 


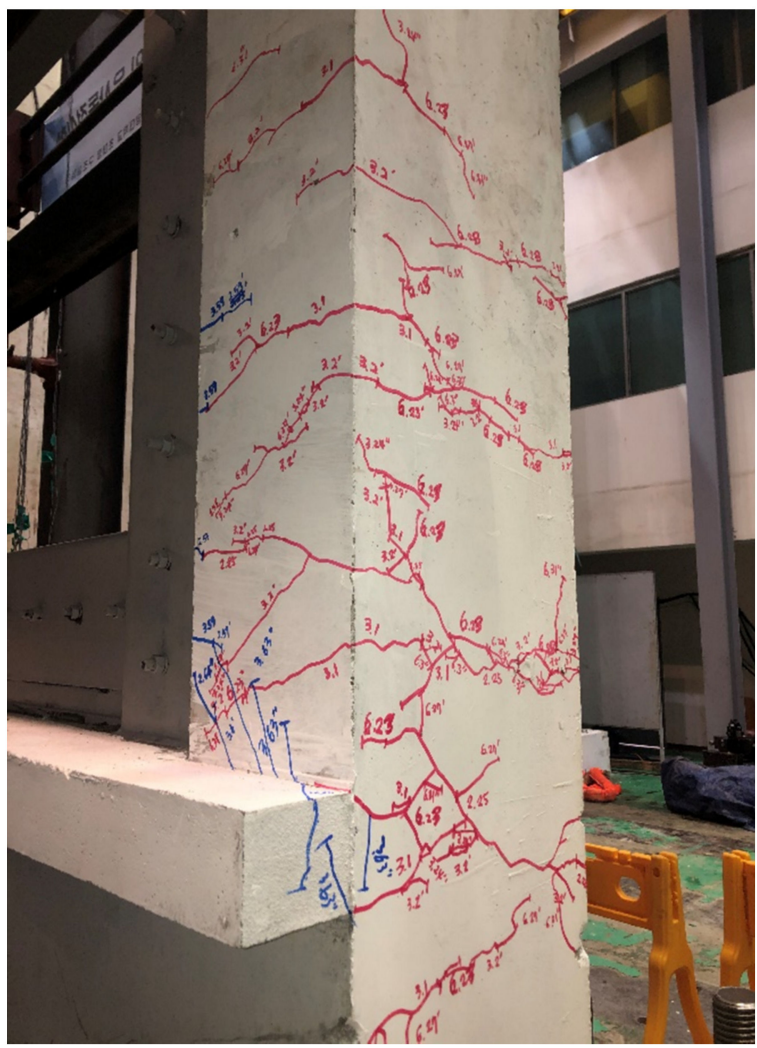

(a)

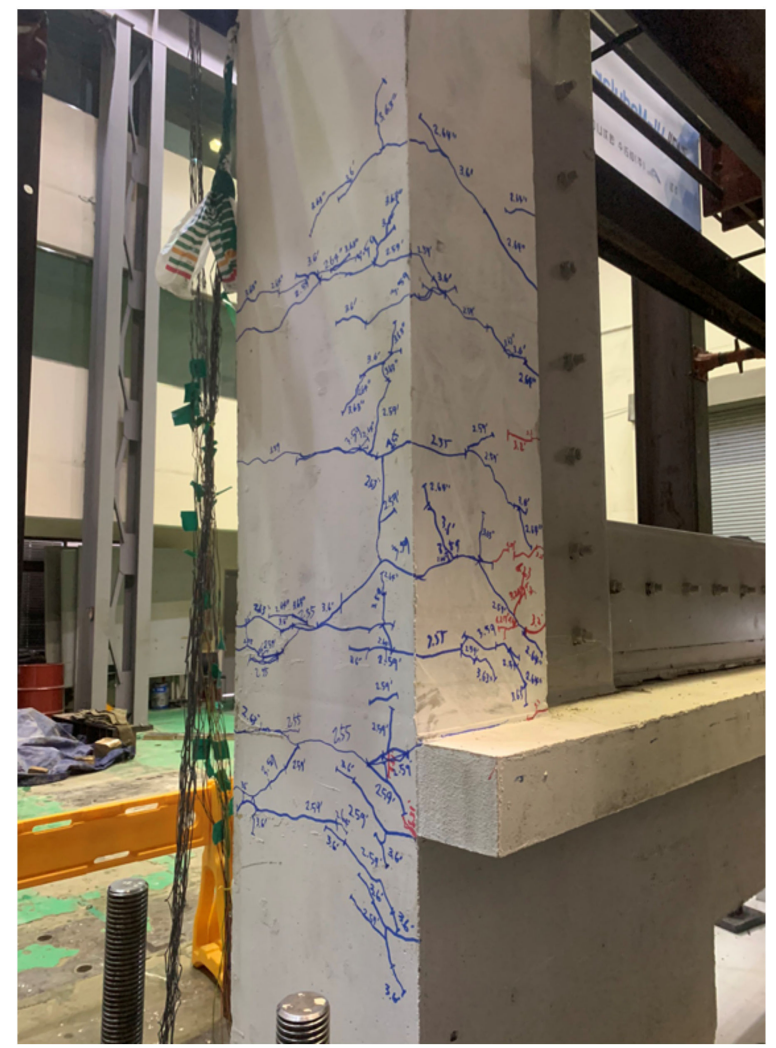

(b)

Figure 13. Cracks and ultimate state of test frame retrofitted with CFT-MF system (PD-CFT) $\left.\left(400 \mathrm{~cm} / \mathrm{s}^{2}\right)\right)$ : (a) severe flexural and shear cracks of the right column and (b) severe flexural and shear cracks of the left column at around $3.63 \mathrm{~s}$.

\subsubsection{Maximum Seismic Response Load and Displacement}

The test frame with no reinforcement applied (PD-FR) was tested at an input seismic ground motion of $200 \mathrm{~cm} / \mathrm{s}^{2}$; the test frame retrofitted with the CFT-MF system (PD-CFTMF) was tested at input seismic ground motions of $200 \mathrm{~cm} / \mathrm{s}^{2}, 300 \mathrm{~cm} / \mathrm{s}^{2}$, and $400 \mathrm{~cm} / \mathrm{s}^{2}$, and the measured maximum response load and displacement were compared with respect to the failure mode and seismic damage, as shown in Table 4.

Table 4. Maximum response load-displacement and degree of seismic damage.

\begin{tabular}{|c|c|c|c|c|c|}
\hline $\begin{array}{l}\text { Specimen } \\
\text { Name }\end{array}$ & $\begin{array}{l}\text { Input Seismic } \\
\text { Ground Motion }\end{array}$ & $\begin{array}{c}\text { Input Seismic } \\
\text { Ground Motion } \\
{\left[\mathrm{cm} / \mathrm{s}^{2}\right]}\end{array}$ & $\begin{array}{c}\text { Maximum Load } \\
\mathbf{V}_{\mathbf{u}}[\mathrm{kN}]\end{array}$ & $\begin{array}{c}\text { Maximum } \\
\text { Displacement } \\
\delta_{\mathbf{u}}[\mathrm{mm}]\end{array}$ & $\begin{array}{c}\text { Degree of Seismic } \\
\text { Damage * } \\
\text { (Failure Mode) }\end{array}$ \\
\hline PD-FR & \multirow{4}{*}{$\begin{array}{l}\text { Hachinohe } \\
\text { (EW) }\end{array}$} & 200 & 250.5 & 58.7 & $\begin{array}{c}\text { Collapse } \\
\text { [Shear collapse] }\end{array}$ \\
\hline \multirow{3}{*}{ PD-CFT-MF } & & 200 & 432.2 & 11.0 & $\begin{array}{c}\text { Light } \\
\text { [Flexural crack] }\end{array}$ \\
\hline & & 300 & 613.3 & 22.4 & $\begin{array}{c}\text { Small } \\
\text { [Flexural and shear } \\
\text { cracks] }\end{array}$ \\
\hline & & 400 & 773.9 & 39.5 & $\begin{array}{c}\text { Moderate } \\
\text { [Flexural and shear } \\
\text { cracks] }\end{array}$ \\
\hline
\end{tabular}

* Degree of seismic damage was determined in accordance with JBDPA [39] and Maeda et al. [40]. 
The pseudo-dynamic test results of PD-FR showed that the maximum seismic response occurred at $250.5 \mathrm{kN}$ (displacement: $58.7 \mathrm{~mm}$ ), when the input seismic ground motion was $200 \mathrm{~cm} / \mathrm{s}^{2}$. Ultimately, a collapse occurred due to shear failure at the columns at around $3.4 \mathrm{~s}$. The degree of seismic damage was considered to be "Collapse" in accordance with JBDPA [39] and Maeda et al. [40].

In the test frame retrofitted with the CFT-MF system (PD-CFT-MF), the maximum seismic response occurred at $432.2 \mathrm{kN}$ (displacement: $11.0 \mathrm{~mm}$ ) when the input seismic ground motion was $200 \mathrm{~cm} / \mathrm{s}^{2}$. The degree of seismic damage was insignificant compared to PD-FR at the same seismic ground motion. At $300 \mathrm{~cm} / \mathrm{s}^{2}$, the maximum seismic response occurred at $613.3 \mathrm{kN}$ (displacement: $22.4 \mathrm{~mm}$ ), and the corresponding degree of seismic damage was determined to be Small in accordance with JBDPA [39] and Maeda et al. [40]. When the input seismic ground motion was $400 \mathrm{~cm} / \mathrm{s}^{2}$, i.e., when a large-scale earthquake was assumed, the maximum seismic response occurred at $773.9 \mathrm{kN}$ (displacement: $39.5 \mathrm{~mm}$ ), the corresponding degree of seismic damage was determined to be "Moderate". These results verify the seismic retrofitting performance of the CFT-MF system even when a large-scale earthquake with a recurrence period of 2400 years occurs.

3.4.3. Comparison and Analysis of Seismic Response Load-Displacement Relationship and Displacement-Time Hysteresis

Figure 14 presents the floor-specific seismic response load-displacement and displacement-time hysteresis curves of the test frame with no reinforcement applied (PDFR) at $200 \mathrm{~cm} / \mathrm{s}^{2}$. Figures 15-17 show the layer-specific seismic response load-displacement and displacement-time hysteresis curves of the test frame retrofitted with the CFT-MF system (PD-CFT-MF) at 200, 300, and $400 \mathrm{~cm} / \mathrm{s}^{2}$, respectively. Figure 18 compares the load-displacement curves obtained from the first floor of both PD-FR at $200 \mathrm{~cm} / \mathrm{s}^{2}$ and PD-CFT-MF at 200, 300, and $400 \mathrm{~cm} / \mathrm{s}^{2}$. Figure 19 compares the displacement-time hysteresis loops of the first floor of both PD-FR at $200 \mathrm{~cm} / \mathrm{s}^{2}$ and PD-CFT-MF at 200, 300, and $400 \mathrm{~cm} / \mathrm{s}^{2}$. Table 5 summarizes the maximum seismic response load and the corresponding response displacement at the maximum load of PD-FR and PD-CFT-MF, along with the comparison of the resultant seismic response strength ratios and displacement ratios, which are important parameters for seismic performance evaluation.

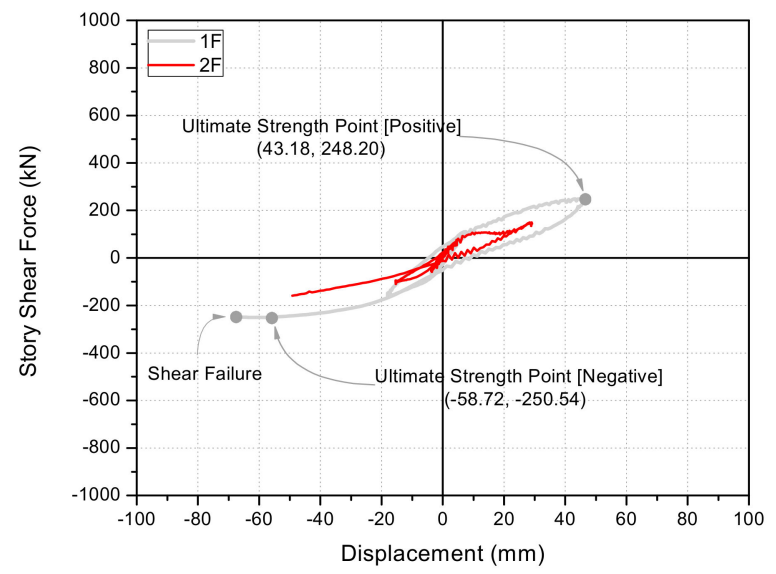

(a)

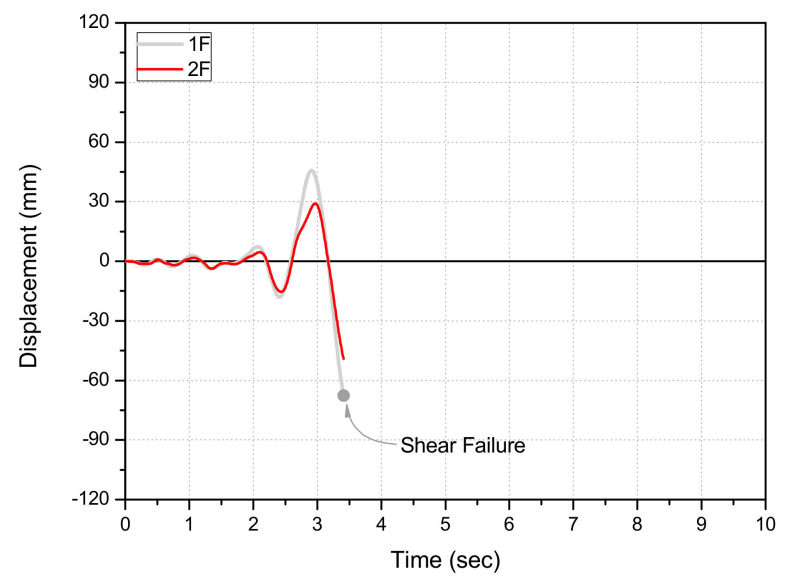

(b)

Figure 14. Seismic response load-displacement and displacement-time hysteresis curves (PD-FR, $\left.200 \mathrm{~cm} / \mathrm{s}^{2}\right)$ : (a) loaddisplacement curves; (b) displacement-time hysteresis curves. 


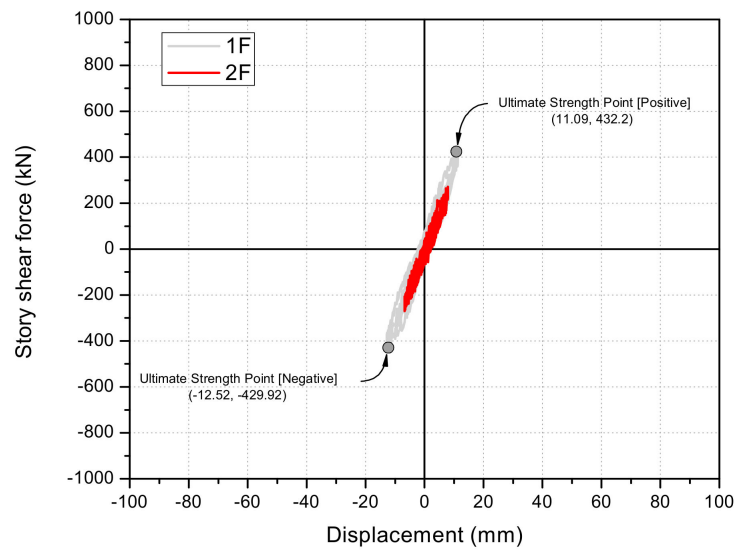

(a)

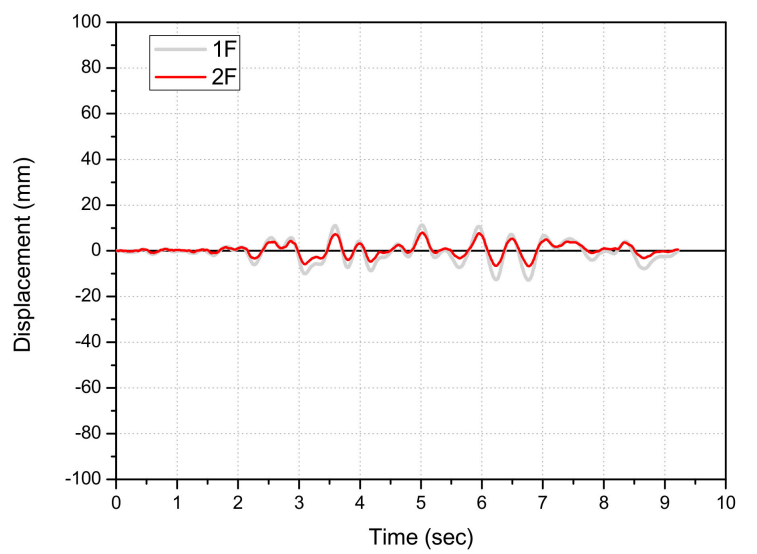

(b)

Figure 15. Seismic response load-displacement and displacement-time hysteresis curves (PD-CFT-MF, $\left.200 \mathrm{~cm} / \mathrm{s}^{2}\right)$ : (a) loaddisplacement curves; (b) displacement-time hysteresis curves.

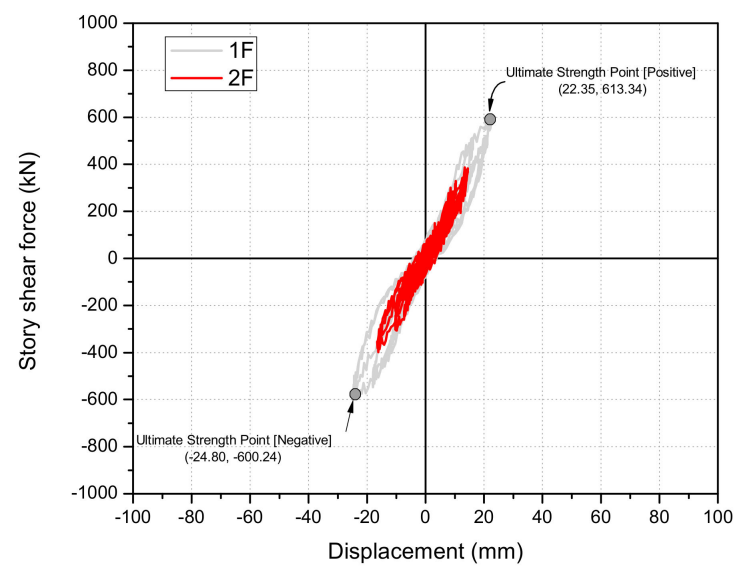

(a)

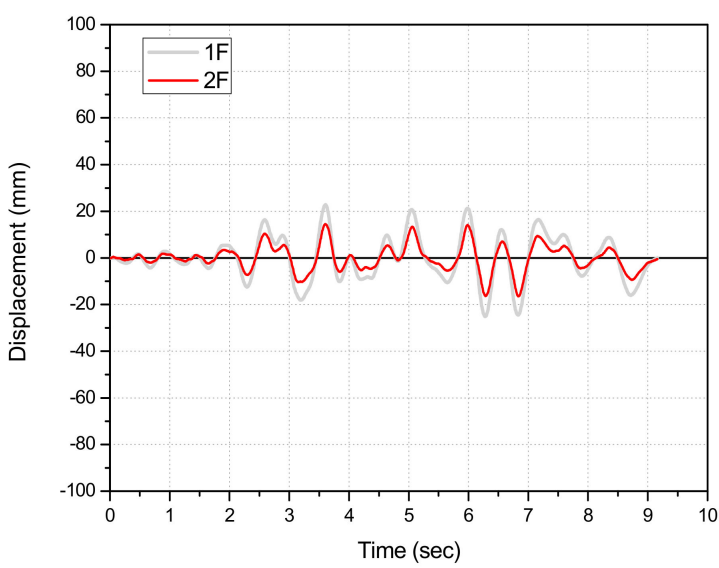

(b)

Figure 16. Seismic response load-displacement and displacement-time hysteresis curves (PD-CFT-MF, $\left.300 \mathrm{~cm} / \mathrm{s}^{2}\right)$ : (a) loaddisplacement curves; (b) displacement-time hysteresis curves.

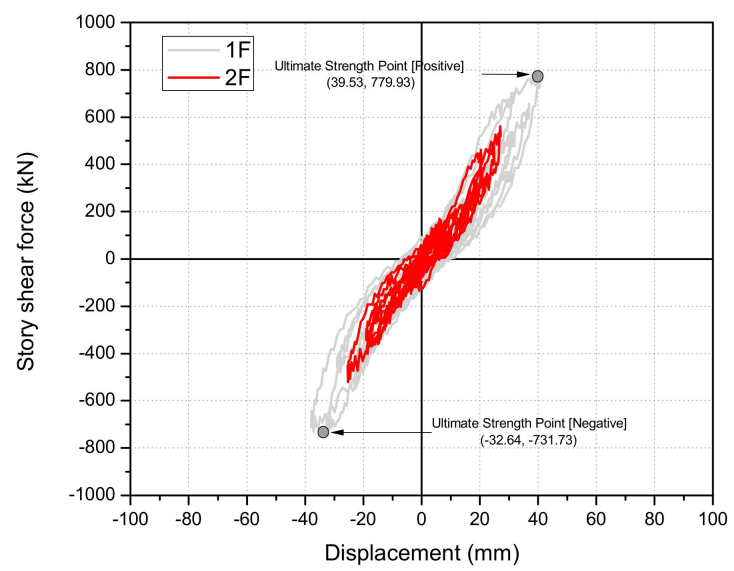

(a)

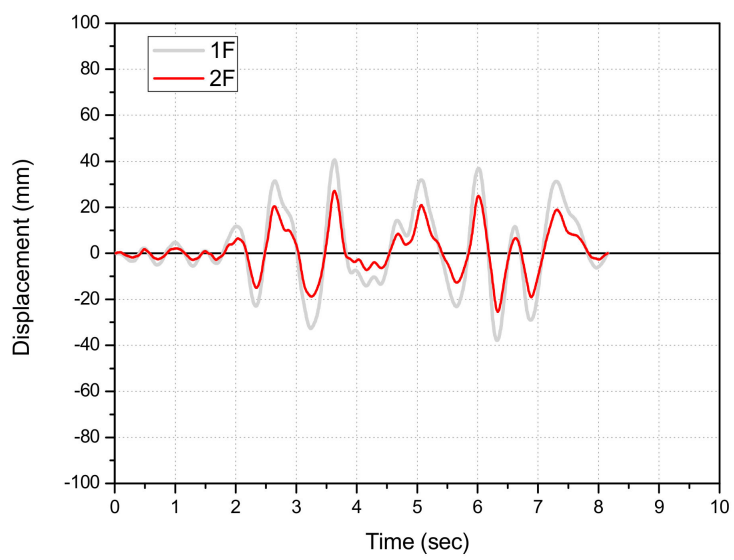

(b)

Figure 17. Seismic response load-displacement and displacement-time hysteresis curves (PD-CFT-MF, $\left.400 \mathrm{~cm} / \mathrm{s}^{2}\right)$ : (a) loaddisplacement curves; (b) displacement-time hysteresis curves. 


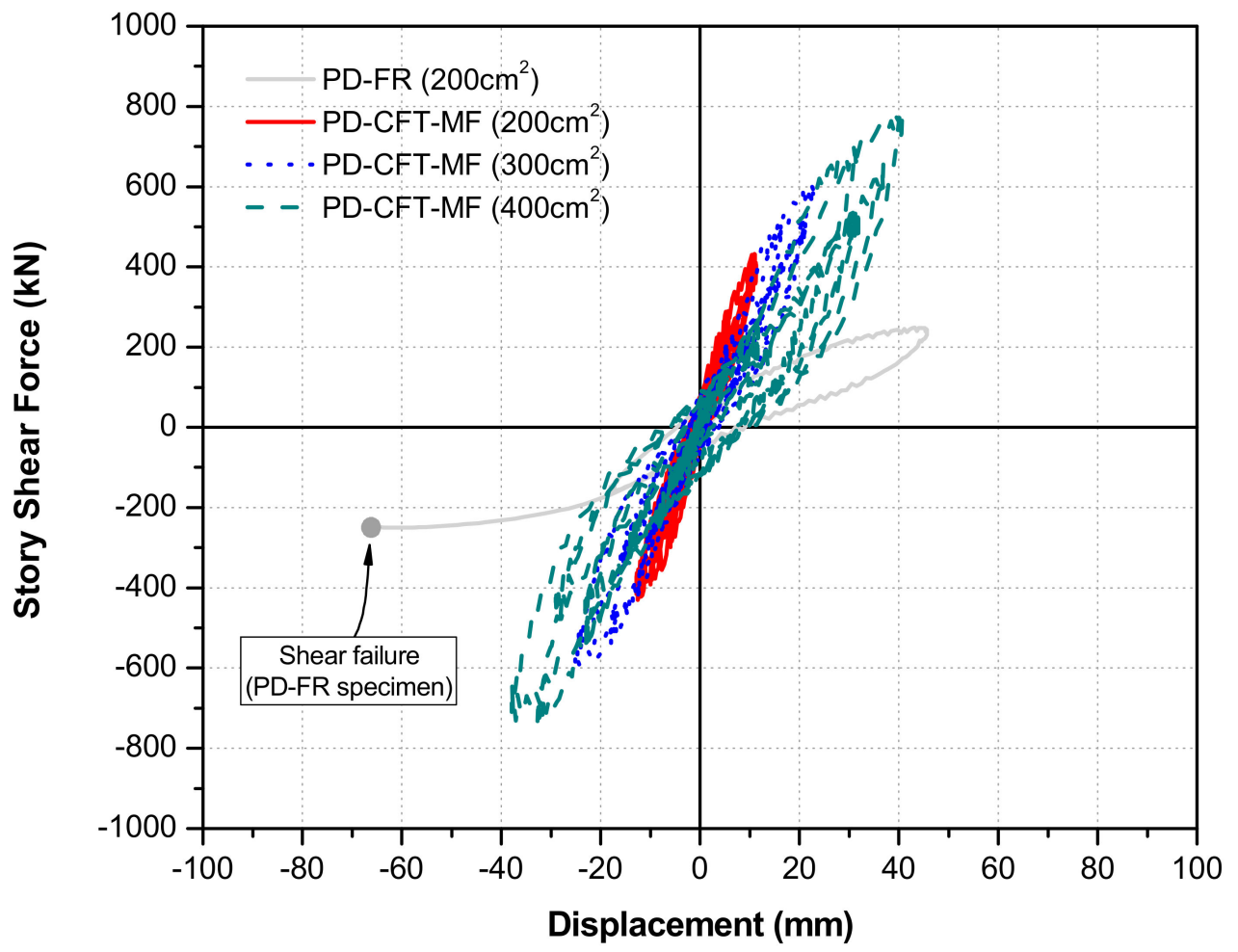

Figure 18. Comparison of seismic response load-displacement curves (first floor).

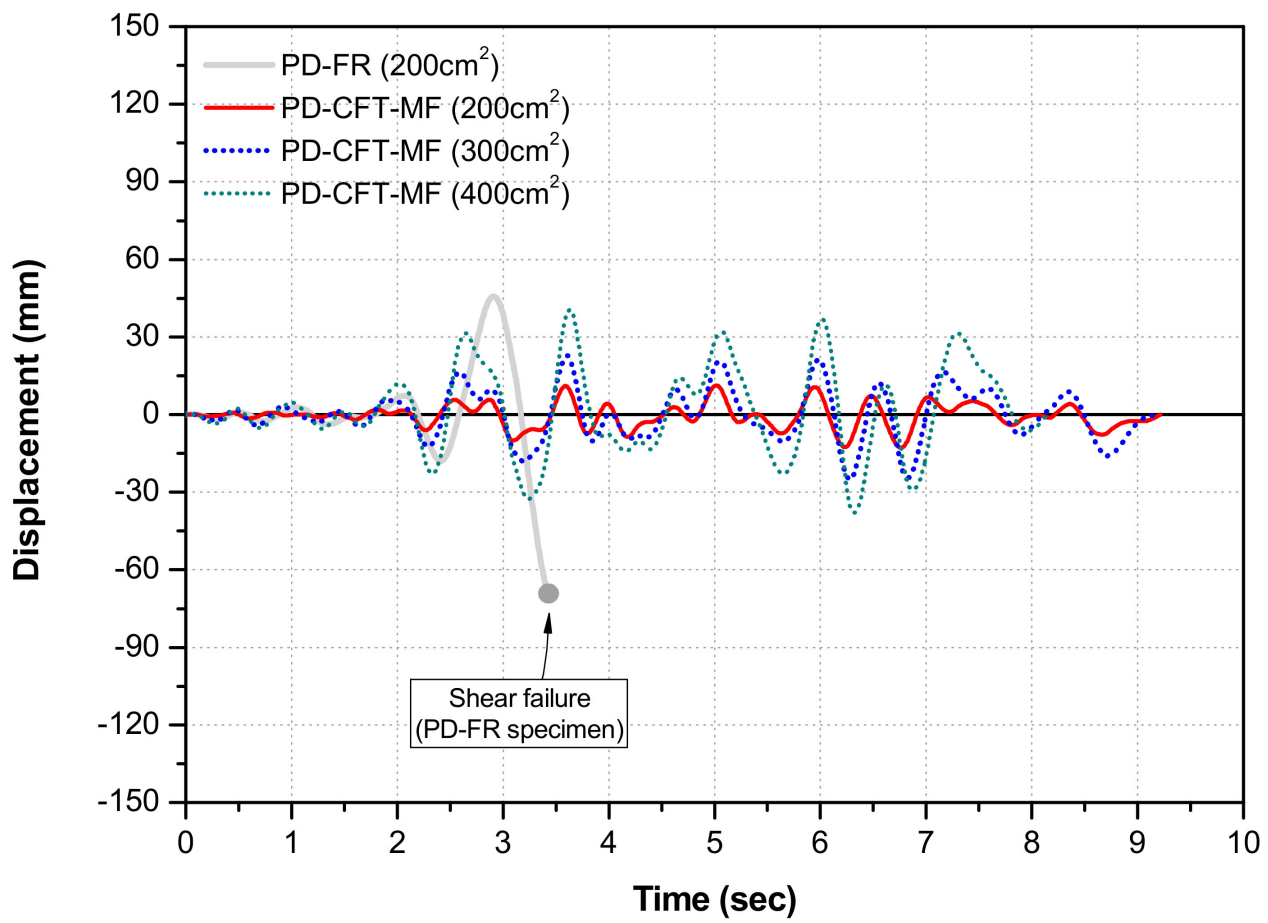

Figure 19. Comparison of seismic response displacement-time hysteresis curves (first floor). 
Table 5. Comparison of maximum seismic response load-displacement results and corresponding seismic response strength and displacement ratios.

\begin{tabular}{cccccc}
\hline \multirow{2}{*}{ Specimen } & \multirow{2}{*}{$\begin{array}{c}\text { Earthquake Levels } \\
\left(\mathbf{c m} / \mathbf{s}^{2}\right)\end{array}$} & \multicolumn{2}{c}{ Response Strength } & \multicolumn{2}{c}{ Response Displacement } \\
\cline { 2 - 6 } & 200 & $\begin{array}{c}\mathbf{V}_{\mathbf{u}} \mathbf{a} \\
{[\mathbf{k N}]}\end{array}$ & $\mathbf{R}_{\mathbf{s}} \mathbf{b}$ & $\begin{array}{c}\boldsymbol{\delta}_{\mathbf{u}} \mathbf{c}^{\mathbf{c}} \\
{[\mathbf{m m}]}\end{array}$ & $\mathbf{R}_{\mathbf{d}} \mathbf{d}$ \\
\hline PD-FR & 200 & 250.5 & $1.00(250.5 / 250.5)$ & 58.7 & $1.00(58.7 / 58.7)$ \\
\hline \multirow{2}{*}{ PD-CFT-MF } & 300 & 432.2 & $1.72(432.2 / 250.5)$ & 11.0 & $0.19(11.0 / 58.7)$ \\
\cline { 2 - 6 } & 400 & 613.3 & $2.45(613.3 / 250.5)$ & 22.4 & $0.38(22.4 / 58.7)$ \\
\cline { 2 - 6 } & 773.9 & $3.09(773.9 / 250.5)$ & 39.5 & $0.67(39.5 / 58.7)$ \\
\hline
\end{tabular}

${ }^{a}$ Maximum response strength. ${ }^{b}$ Ratio of maximum response shear strength between strengthened and reference specimens with respect to earthquake intensity. ${ }^{\mathrm{c}}$ Response displacement at maximum point. ${ }^{\mathrm{d}}$ Ratio of response displacement between strengthened and reference specimens with respect to earthquake intensity.

According to the figures and table below, the test frame retrofitted with the CFTMF system exhibited seismic response strength about 1.72 times higher than that of the reference test frame (PD-FR) when the same seismic acceleration was applied at $200 \mathrm{~cm} / \mathrm{s}^{2}$. The difference was even larger when the seismic acceleration was higher: about 2.45 times at $300 \mathrm{~cm} / \mathrm{s}^{2}$ and about 3.09 times at $400 \mathrm{~cm} / \mathrm{s}^{2}$. PD-CFT-MF also exhibited smaller seismic response displacements than the reference test frame. The difference was about 0.19 times at $200 \mathrm{~cm} / \mathrm{s}^{2}$, about 0.38 times at $300 \mathrm{~cm} / \mathrm{s}^{2}$, and 0.67 times at $400 \mathrm{~cm} / \mathrm{s}^{2}$. The results confirmed that when the same seismic acceleration was applied at $200 \mathrm{~cm} / \mathrm{s}^{2}$, the seismic response displacement was about $81 \%$ lower in PD-CFT-MF than in the reference frame PD-FR. This indicates that the CFT-MF system was able to effectively enhance the ability of the test frame to absorb the applied seismic energy.

\section{Comparison of Pseudo-Dynamic Test Results and Non-Linear Dynamic Analysis Results}

Based on the pseudo-dynamic test results obtained from PD-CFT-MF, the test frame retrofitted with the CFT-MF system, described in Chapter 3, the restoring force characteristics of beams, columns, and reinforcing members were proposed to implement non-linear dynamic analysis of the full-size two-story test frame retrofitted with the CFT-MF seismic retrofitting method. The proposed restoring force characteristics were used to conduct non-linear dynamic analysis of the two-story pseudo-dynamic test frame, and the results were then compared with the pseudo-dynamic test results.

\subsection{Overview of Non-linear Dynamic Analysis}

Non-linear dynamic analysis was conducted on both the full-size two-story RC frame with no reinforcement applied, and the test frame retrofitted with the CFT-MF system shown in Figures 8 and 9 in Section 3.2. In reality, actual structures vibrate in a threedimensional and complex manner; however, in the present study, it was assumed that the used columns, beams, and walls were wire-type materials so that the test frame was modeled as a plane frame, in which only the seismic force in the horizontal direction was considered. The floor-specific structural evaluation was conducted at the member level, and the following assumptions were applied in the analysis. (1) The position of each member's yield hinges was determined based on references (JBDPA, [29] and AIJ [41]), and the segment from the center of each member, including column and beam joints, to the ends of the members, where yield hinges occur, shall be assumed to be rigid. (2) The strength of a beam shall be determined considering the effect of the slab reinforcing bars present within the effective width of the slabs that collaborate with the corresponding beam. (3) Each member shall be modelled to allow flexural springs, shear springs, and axial springs to be serially connected, as shown in Figure 20. 


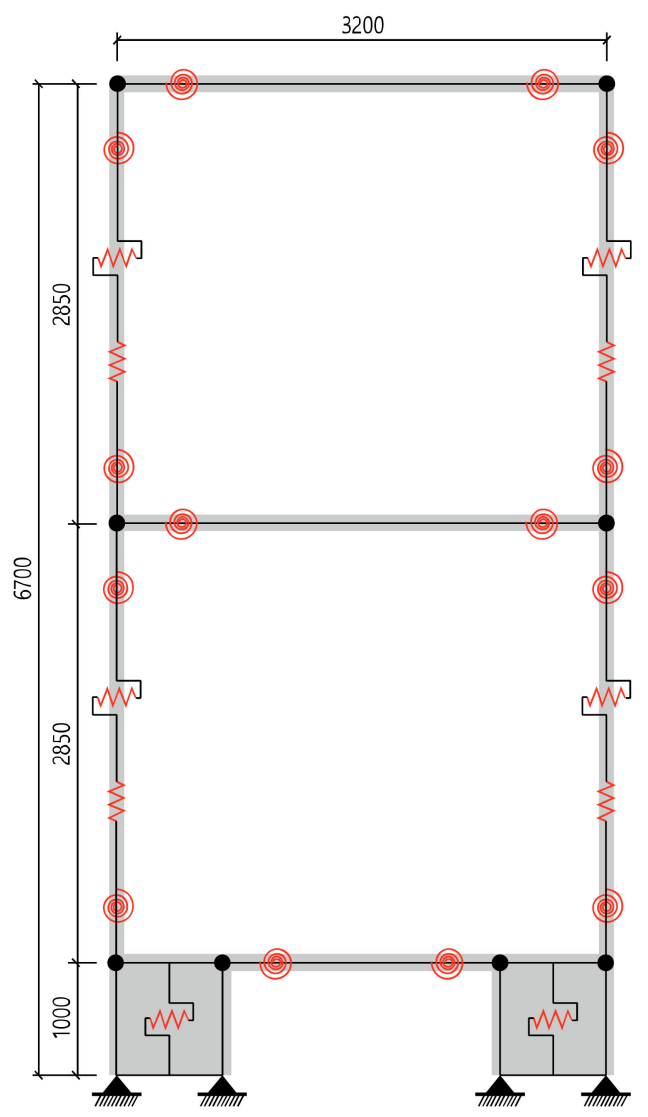

(a)

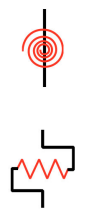

Flexural Spring

Shear Spring

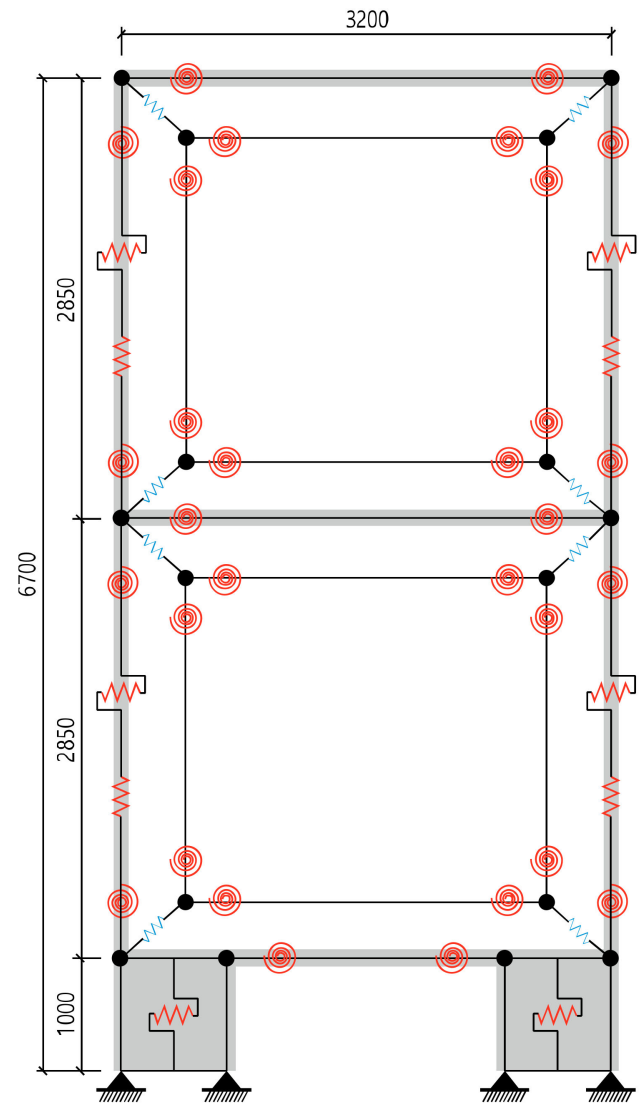

(b)

$\xi$

Axial Spring

$\xi$

Connection Link Spring

Figure 20. Non-linear dynamic analysis models: (a) control specimen (PD-FR); (b) PD-CFT-MF.

The test frame with no reinforcement applied (PD-FR) includes ground beams and walls on the foundation level. It is composed of a total of 12 nodal points, including two deck panels and branch points, as shown in Figure 20a. The test frame retrofitted with the CFT-MF system (PD-CFT-MF) includes the members that connect the existing RC frame with the CFT-MF reinforcing members in addition to the nodal points of the test frame with no reinforcement applied, as shown in Figure 20b. Thus, it is composed of a total of 20 nodal points, including branch points. The anchor bolt used to connect the existing RC members with the CFT-MF reinforcing members was modeled as a link-joint element.

In non-linear dynamic analysis, the axial force was determined based on the axial load exerted on the actual existing frame (two columns), i.e., 1000-kN. Thus, each of the upper beam-column connection nodes was subjected to a constant axial force of 500-kN. Also, the additional weight of the RC frame and the CFT-MF reinforcing bars was exerted on the corresponding nodal points.

Non-linear dynamic analysis was performed using CNAAY, a commercial software package developed by Li [42] to implement the three-dimensional non-linear dynamic analysis. Table 6 presents an overview of the restoring force characteristics of each member used in non-linear dynamic analysis. 
Table 6. Restoring force characteristics of each member used in non-linear dynamic analysis (Li [42]).

\begin{tabular}{cccc}
\hline \multirow{2}{*}{ Member } & \multicolumn{2}{c}{ Restoring Force Model } & Model Name \\
\hline \multirow{2}{*}{ Beam } & Flexural spring & CP3 & Cross-peak trilinear model \\
\cline { 2 - 4 } & Shear spring & OO3 & Trilinear origin-oriented \\
\hline \multirow{2}{*}{ Column } & Flexural spring & CA7 & $\begin{array}{c}\text { CANNY sophisticated trilinear } \\
\text { hysteresis model }\end{array}$ \\
\cline { 2 - 4 } & Shear spring & OO3 & Trilinear origin-oriented \\
\cline { 2 - 4 } & Axial spring & AE1 & Axial stiffness model \\
\hline Wall & Shear spring & OO3 & Trilinear origin-oriented \\
\hline Anchor bolt & Shear spring & EL2 & Bilinear elastic model \\
\hline \multirow{2}{*}{ CFT-MF } & Flexural spring & SL2 & Bilinear slip model (SL2) \\
\cline { 2 - 4 } & Shear spring & EL1 & Linear elastic model \\
\hline
\end{tabular}

The parameters that determine the restoring force characteristics of each column and beam, as shown in Table 6, including the initial flexural stiffness $\left(\mathrm{k}_{\mathrm{B}}\right)$, initial shear stiffness $\left(k_{S}\right)$, flexural crack moment $\left(M_{c}\right)$, shear crack strength $\left(V_{c}\right)$, ultimate flexural strength $\left(M_{u}\right)$, and ultimate shear strength $\left(\mathrm{V}_{\mathrm{u}}\right)$ were estimated using Equations (5)-(12) in accordance with JBDPA [29] and AIJ [41].

4.1.1. Determination of Flexural Restoring Force Characteristics

$$
\begin{gathered}
M_{c}=0.63 \sqrt{F_{c}} Z \phi(\text { Beam }) \\
M_{c}=0.63 \sqrt{F_{c}} Z+N D / 6(\text { Column }) \\
M_{u}=0.9 a_{t} \sigma_{y} d(\text { Beam }) \\
M_{u}=0.8 a_{t} \sigma_{y} D+0.5 N D\left(1-\frac{N}{b D F_{c}}\right) \text { (Column) } \\
k_{B}=6 E I / l \text { (Both beam and column) }
\end{gathered}
$$

where, $M_{c}$ : flexural crack moment $(\mathrm{N} \cdot \mathrm{mm}), M_{u}$ : ultimate flexural moment $(\mathrm{N} \cdot \mathrm{mm}), k_{B}$ : initial flexural stiffness $(\mathrm{N} / \mathrm{mm}), F_{c}$ : compressive strength of concrete $\left(\mathrm{N} / \mathrm{mm}^{2}\right), Z$ : section modulus $\left(\mathrm{mm}^{3}\right), \phi$ : shape factor of the beam, $N$ : axial force $(\mathrm{N}), D$ : column depth $(\mathrm{mm})$, $a_{t}$ : total cross-sectional area of the tensile reinforcing bars $\left(\mathrm{mm}^{2}\right), \sigma_{y}$ : yield strength of the reinforcing bars $\left(\mathrm{N} / \mathrm{mm}^{2}\right)$, and d: effective depth $(\mathrm{mm})$.

4.1.2. Determination of Shear Restoring Force Characteristics

$$
\begin{gathered}
V_{c}=\left\{\frac{\left(1+\frac{\sigma_{0}}{15}\right) 0.065 k_{c}\left(50+F_{c}\right)}{\frac{M}{V d}+1.7}\right\} b j\left(\text { Both beam and column, if beam, } \sigma_{0}=0\right) \\
V_{u}=\left\{\frac{0.053 p_{t}^{0.023}\left(18+F_{c}\right)}{\frac{M}{V d}+0.12}+0.85 \sqrt{p_{w s} \cdot \sigma_{w y}}+0.1 \sigma_{0}\right\} b j\left(\text { Both beam and column, if beam, } \sigma_{0}=0\right) \\
k_{s}=G A / \kappa(\text { Both beam and column) }
\end{gathered}
$$

where, $V_{c}$ : shear crack strength $(\mathrm{N} \cdot \mathrm{mm}), V_{u}$ : ultimate shear strength $(\mathrm{N}), k_{B}$ : initial shear stiffness $(\mathrm{N} / \mathrm{mm}), \sigma_{0}$ : axial stress in the column $\left(\mathrm{N} / \mathrm{mm}^{2}\right), k_{c}$ : modification coefficient depending on the cross-section, $b$ : width $(\mathrm{mm}), j$ : distance between centroids of tension and compressive force $(\mathrm{mm}), p_{t}$ : tensile reinforcement ratio (percent), $p_{w s}$ : shear reinforcement ratio ( $p_{w s}=0.012$ for $\left.\mathrm{Pw} \geq 0.012\right), \sigma_{w y}$ : yield strength of the shear reinforcing bars 
$\left(\mathrm{N} / \mathrm{mm}^{2}\right), \mathrm{M} / \mathrm{V}$ : shear span length; the default value is $=\mathrm{h}_{\mathrm{o}} / 2$, and $\mathrm{h}_{\mathrm{o}}$ : clear height of the column (mm).

\subsection{Comparison of Non-linear Dynamic Analysis and Pseudo-Dynamic Test Results}

Non-linear dynamic analysis was performed using the Hachinohe wave (EW) at 200, 300 , and $400 \mathrm{~cm} / \mathrm{s}^{2}$ applied in the pseudo-dynamic tests. Further, the model described in Section 4.1, along with CANNY, was employed. As mentioned previously, $200 \mathrm{~cm} / \mathrm{s}^{2}$ of the Hachinohe wave (EW) was applied to the test frame with no reinforcement applied (PD-FR) in the pseudo-dynamic testing, while 200,300 , and $400 \mathrm{~cm} / \mathrm{s}^{2}$ of the Hachinohe wave (EW) were applied in the test frame retrofitted with the CFT-MF system (PD-CFT-MF). Figure 21 shows the seismic response load-displacement and time-displacement curves obtained from the first floor of the test frame with no reinforcement applied during non-linear dynamic analysis and pseudo-dynamic tests when the input seismic ground motion was $200 \mathrm{~cm} / \mathrm{s}^{2}$. Figures 22-24 show the seismic response load-displacement and time-displacement curves obtained from the first floor of the test frame retrofitted with the CFT-MF system during non-linear dynamic analysis and pseudo-dynamic tests when the input seismic ground motion was 200,300 , and $400 \mathrm{~cm} / \mathrm{s}^{2}$, respectively. Table 7 compares the maximum response load-displacement relationship between non-linear dynamic analysis and pseudo-dynamic test results.

Figure 25 shows a contribution comparison of the lateral response load in terms of displacement relationships among the RC frame strengthened with the CFT-MF system, the CFT-MF system, and the un-reinforced RC frame. In the figure, the skeleton curves of lateral response load-displacement for the RC frame strengthened with the CFT-MF system were derived from both the non-linear dynamic analysis and the pseudo-dynamic test at $300 \mathrm{~cm} / \mathrm{s} 2$, respectively. In contrast, the load-displacement curve of the CFT-MF system was derived based on the non-linear dynamic analysis results, because it could not be measured in pseudo-dynamic testing. The restoring force of the RC frame with no reinforcement applied, as shown in Figure 25, was derived based on non-linear seismic response analysis and pseudo-dynamic test results at $200 \mathrm{~cm} / \mathrm{s}^{2}$. In the $\mathrm{RC}$ frame with no reinforcement applied, a shear collapse occurred at the lower part of the first floor, as shown in Figure 10. Table 4 shows and compares the contribution of the seismic response load of each member to the response displacement determined based on Figure 25.

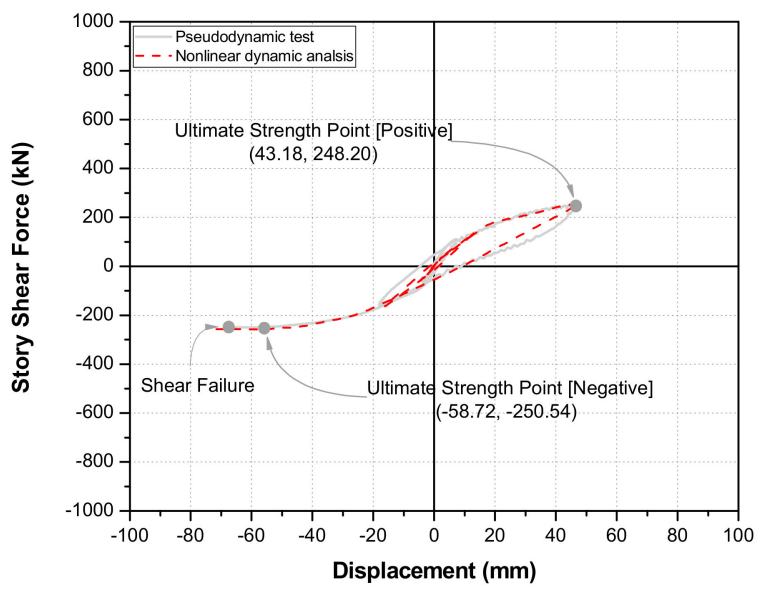

(a)

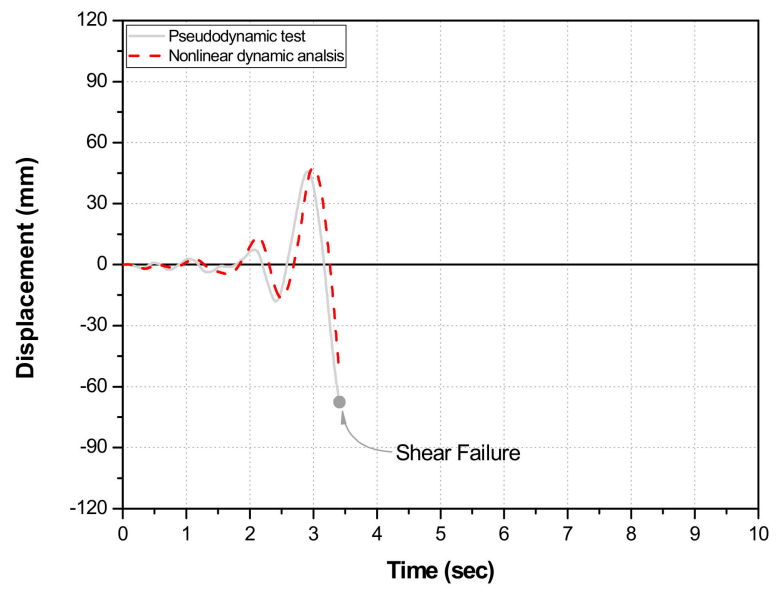

(b)

Figure 21. Comparison of non-linear dynamic analysis and pseudo-dynamic test results of RC frame with no reinforcement applied (PD-FR) (first floor, $200 \mathrm{~cm} / \mathrm{s}^{2}$ ): (a) load-displacement curves; (b) displacement-time hysteresis curves. 


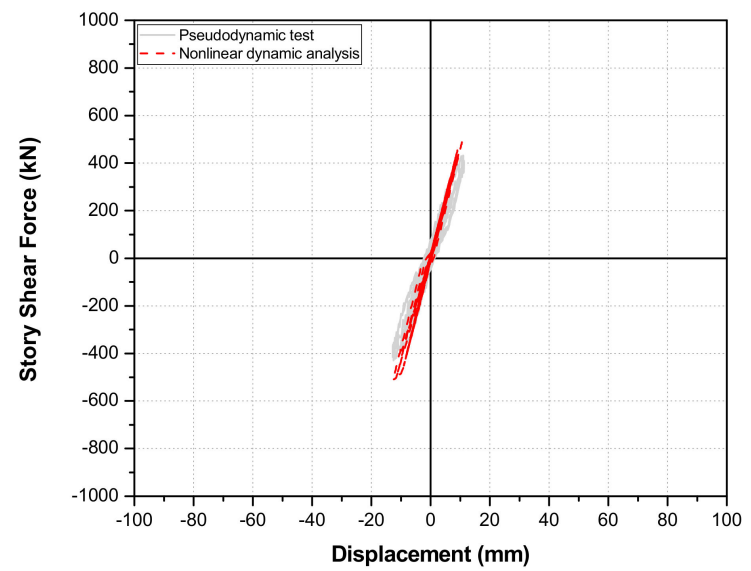

(a)

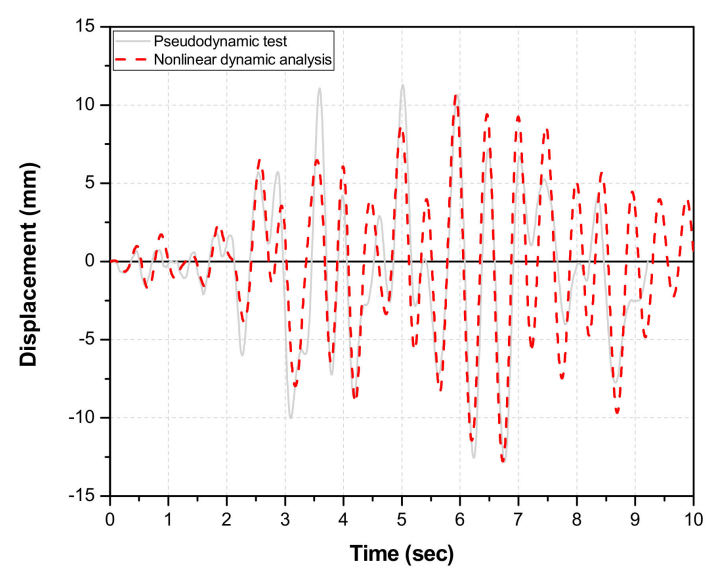

(b)

Figure 22. Comparison of non-linear dynamic analysis and pseudo-dynamic test results of test frame retrofitted with the CFT-MF system (PD-CFT-MF) (first floor, $200 \mathrm{~cm} / \mathrm{s}^{2}$ ): (a) load-displacement curves; (b) displacement-time hysteresis curves.

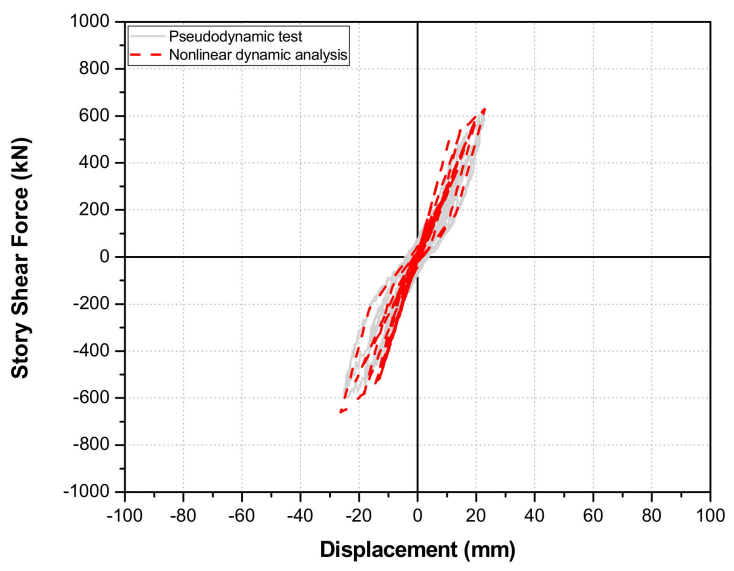

(a)

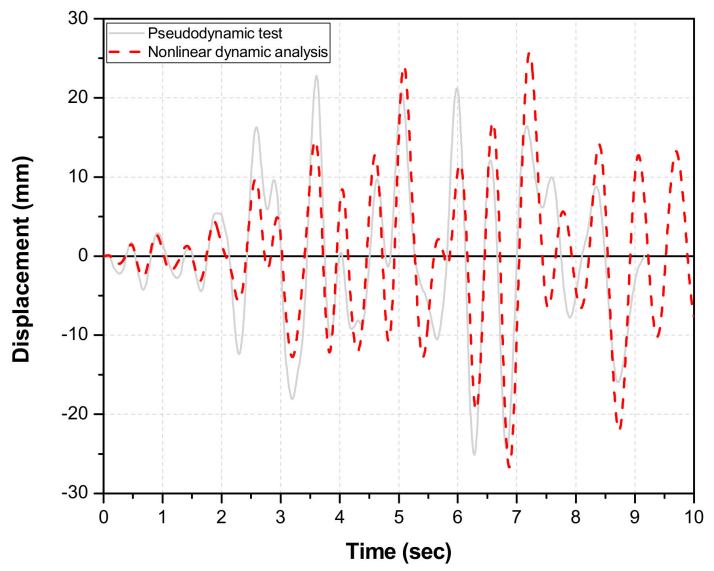

(b)

Figure 23. Comparison of non-linear dynamic analysis and pseudo-dynamic test results of test frame retrofitted with CFT-MF system (PD-CFT-MF) (first floor, $300 \mathrm{~cm} / \mathrm{s}^{2}$ ): (a) load-displacement curves; (b) displacement-time hysteresis curves.

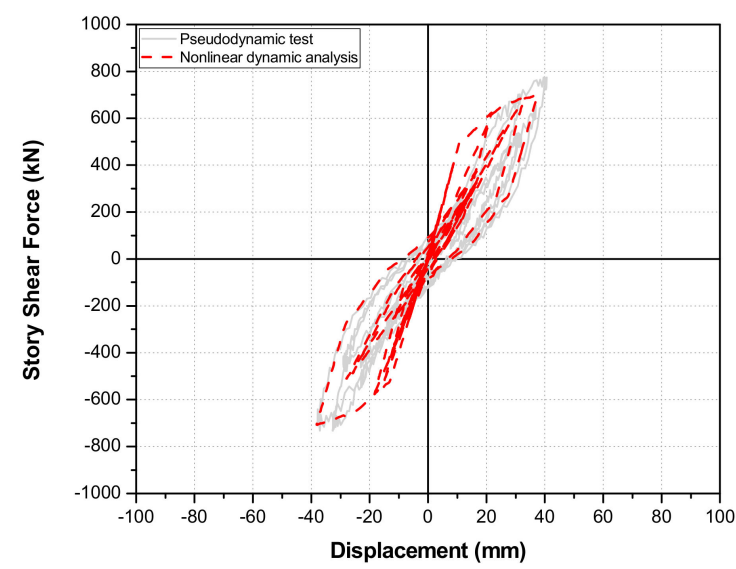

(a)

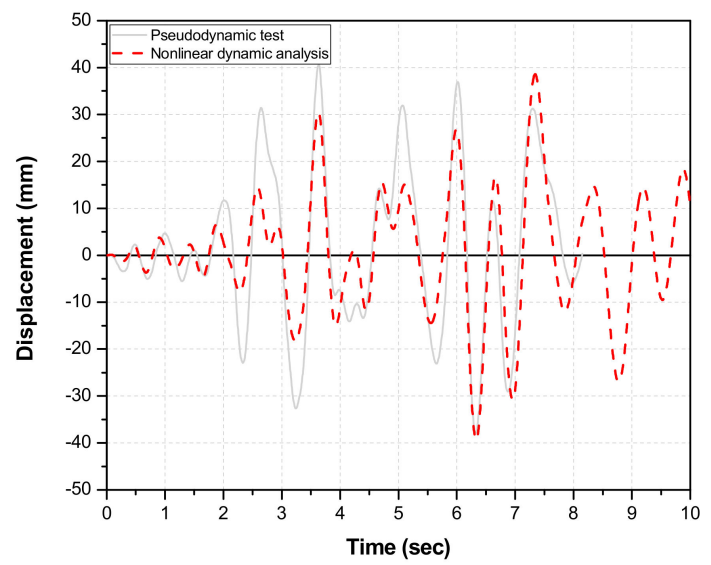

(b)

Figure 24. Comparison of non-linear dynamic analysis and pseudo-dynamic test results of the test frame retrofitted with the CFT-MF system (PD-CFT-MF) (first floor, $400 \mathrm{~cm} / \mathrm{s}^{2}$ ): (a) load-displacement curves; (b) displacement-time hysteresis curves. 
Table 7. Comparison of maximum response load-displacement relationship between non-linear dynamic analysis and pseudo-dynamic test results.

\begin{tabular}{|c|c|c|c|c|c|c|}
\hline $\begin{array}{l}\text { Speci- } \\
\text { men }\end{array}$ & $\begin{array}{c}\text { Input Seismic Accele- } \\
\text { Ration } \\
{\left[\mathrm{cm} / \mathrm{s}^{2}\right]}\end{array}$ & Method & $\begin{array}{c}\text { Maximum } \\
\text { Displacement } \\
{[\mathrm{mm}]}\end{array}$ & $\begin{array}{c}\text { Deviation Ratio } \\
\text { in Terms of Maximum } \\
\text { Displacement } * 1 \\
\text { [Analytical/Exp- } \\
\text { Erimental] }\end{array}$ & $\begin{array}{l}\text { Maximum } \\
\text { Load } \\
{[\mathbf{k N}]}\end{array}$ & $\begin{array}{l}\text { Deviation Ratio } \\
\text { in Terms of } \\
\text { Maximum Load } * 1 \\
\text { [Analytical/Exp- } \\
\text { Erimental] }\end{array}$ \\
\hline \multirow{2}{*}{ PD-FR } & \multirow{2}{*}{200} & PDT $* 2$ & 66.4 & \multirow{2}{*}{$\begin{array}{c}1.08 \\
(71.6 / 66.4)\end{array}$} & 250.5 & \multirow{2}{*}{$\begin{array}{c}1.03 \\
(258.1 / 250.5)\end{array}$} \\
\hline & & $\mathrm{NDA}^{* 2}$ & 71.6 & & 258.1 & \\
\hline \multirow{6}{*}{$\begin{array}{l}\text { PD-CFT- } \\
\text { MF }\end{array}$} & \multirow{2}{*}{200} & PDT *2 & 12.8 & \multirow{2}{*}{$\begin{array}{c}1.00 \\
(12.7 / 12.8)\end{array}$} & 432.2 & \multirow{2}{*}{$\begin{array}{c}1.18 \\
(514.8 / 432.2)\end{array}$} \\
\hline & & $\mathrm{NDA}^{* 2}$ & 12.7 & & 514.8 & \\
\hline & \multirow{2}{*}{300} & $\mathrm{PDT}^{* 2}$ & 25.1 & \multirow{2}{*}{$\begin{array}{c}1.06 \\
(26.7 / 25.1)\end{array}$} & 613.3 & \multirow{2}{*}{$\begin{array}{c}1.08 \\
(662.5 / 613.3)\end{array}$} \\
\hline & & $\mathrm{NDA}^{* 2}$ & 26.7 & & 662.5 & \\
\hline & \multirow{2}{*}{400} & PDT *2 & 40.6 & \multirow{2}{*}{$\begin{array}{c}0.97 \\
(39.4 / 40.6)\end{array}$} & 773.9 & \multirow{2}{*}{$\begin{array}{c}0.92 \\
(712.4 / 773.9)\end{array}$} \\
\hline & & $\mathrm{NDA}^{* 2}$ & 39.4 & & 712.4 & \\
\hline
\end{tabular}

$* 1$ The deviation ratio refers to the ratio of the maximum response strength (or displacement) obtained in the non-linear dynamic analysis to the maximum response strength (or displacement) obtained in the pseudo-dynamic testing. ${ }^{* 2}$ PDT and NDA show the pseudo-dynamic test and the non-linear dynamic analysis, respectively.

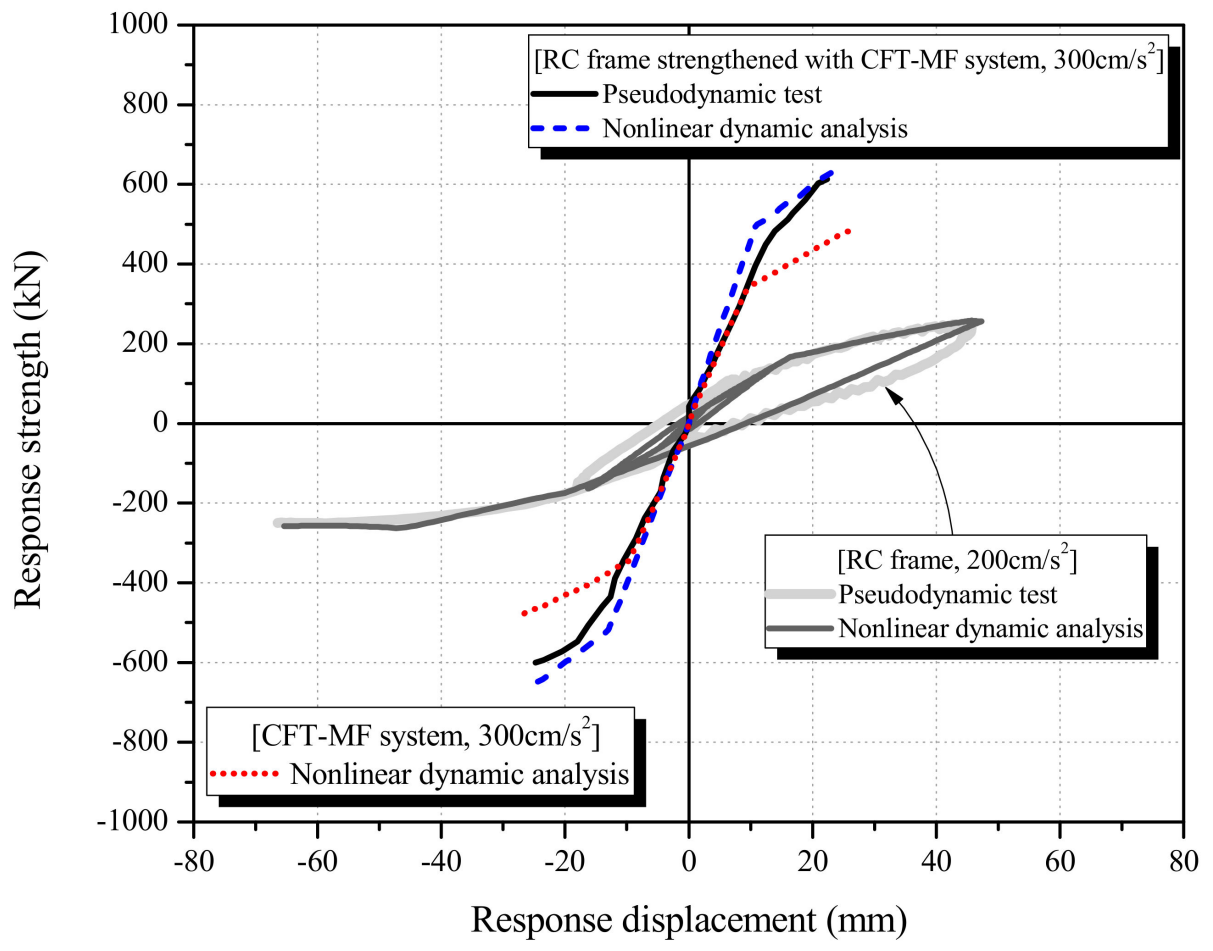

Figure 25. Comparison of contribution of seismic response load of each member to seismic response displacement (RC test frame retrofitted with CFT-MF system, CFT-MF system, and RC test frame with no reinforcement applied).

When the input seismic acceleration was $200 \mathrm{~cm} / \mathrm{s}^{2}$, the maximum seismic response load and displacement of the test frame with no reinforcement applied (PD-FR) were $258.1 \mathrm{kN}$ and $71.6 \mathrm{~mm}$, respectively, in the non-linear dynamic analysis and $250.5 \mathrm{kN}$ and $66.4 \mathrm{~mm}$, respectively, in the pseudo-dynamic testing (Figure 21 and Table 7). When the input seismic acceleration was $200 \mathrm{~cm} / \mathrm{s}^{2}$, the maximum seismic response load and displacement of the test frame retrofitted with the CFT-MF system (PD-CFT-MF) were $514.8 \mathrm{kN}$ and $12.7 \mathrm{~mm}$, respectively, in the non-linear dynamic analysis and $432.2 \mathrm{kN}$ and $12.8 \mathrm{~mm}$, respectively, in the pseudo-dynamic testing (Figure 22 and Table 7). At a seismic ground motion of $200 \mathrm{~cm} / \mathrm{s}^{2}$, the deviation between the non-linear dynamic analysis and 
pseudo-dynamic test results was not significant at $10 \%$ or less on average. When the input seismic acceleration was $300 \mathrm{~cm} / \mathrm{s}^{2}$, the maximum seismic response load and displacement of PD-CFT-MF were $662.5 \mathrm{kN}$ and $26.7 \mathrm{~mm}$, respectively, in the non-linear dynamic analysis and $613.3 \mathrm{kN}$ and $25.1 \mathrm{~mm}$, respectively, in the pseudo-dynamic testing (Figure 23 and Table 7). The two methods provided similar results. When the input seismic acceleration was $400 \mathrm{~cm} / \mathrm{s}^{2}$ as well, i.e., when a large-scale earthquake was assumed, the maximum seismic response load and displacement were $712.4 \mathrm{kN}$ and $39.4 \mathrm{~mm}$, respectively, in the non-linear dynamic analysis and $773.9 \mathrm{kN}$ and $40.6 \mathrm{~mm}$, respectively, in the pseudodynamic testing (Figure 24 and Table 7). The anchor bolts connecting the existing RC members with the CFT-MF reinforcing bars were assumed to follow the bi-linear elastic model, as shown in Table 6. These anchor bolts exhibited elastic behavior over the entire seismic ground motion range.

These results confirmed that the non-linear dynamic analysis model and methodology developed in the present study were able to effectively simulate the seismic behavior of the CFT-MF system and RC frames retrofitted with the system. This led to the conclusion that the seismic retrofitting performance of the CFT-MF system developed in the present study could be effectively evaluated via non-linear dynamic analysis based on the analytical models and methods established in Section 4.1.

The contribution of the seismic response load of each member (including the CFT-MF system developed in the present study and the RC test frame retrofitted with the CFT-MF system) to the seismic response displacement at a seismic ground motion of $300 \mathrm{~cm} / \mathrm{s}^{2}$ is presented in Table 8 and Figure 25. The contribution ratios of the lateral load of the CFT-MF system were $72.0 \%, 72.3 \%$, and $73.5 \%$ when the displacement was $10 \mathrm{~mm}, 20 \mathrm{~mm}$, and $30 \mathrm{~mm}$, respectively.

Table 8. Contribution of each member's load to seismic response displacement determined based on Figure 25.

\begin{tabular}{|c|c|c|c|c|}
\hline \multirow{3}{*}{$\begin{array}{l}\text { Displacement Point } \\
\qquad(\mathrm{mm})\end{array}$} & \multicolumn{3}{|c|}{ Lateral Response Strength $(\mathbf{k N})$} & \multirow{3}{*}{$\begin{array}{l}\text { Contribution } \\
\text { Ratio of vs. * } \\
\quad(\%)\end{array}$} \\
\hline & \multicolumn{2}{|c|}{$300 \mathrm{~cm} / \mathrm{s}^{2}$} & \multirow{2}{*}{$\begin{array}{c}200 \mathrm{~cm} / \mathrm{s}^{2} \\
\text { Non-Reinforced } \\
\text { Frame } \\
{\left[\mathrm{V}_{\mathrm{N}}\right]}\end{array}$} & \\
\hline & $\begin{array}{c}\text { RC Frame Strengthened } \\
\text { with CFT-MF System } \\
{\left[\mathrm{V}_{\mathrm{T}}\right]}\end{array}$ & $\begin{array}{l}\text { CFT-MF } \\
\text { System } \\
{\left[\mathrm{V}_{\mathrm{S}}\right]}\end{array}$ & & \\
\hline 10 & 486.8 & 350.7 & 136.1 & 72.0 \\
\hline 20 & 602.9 & 435.8 & 167.1 & 72.3 \\
\hline 30 & 679.6 & 499.6 & 180.1 & 73.5 \\
\hline
\end{tabular}

* The contribution ratio refers to the ratio of the response strength of the CFT-MF system $\left(\mathrm{V}_{\mathrm{S}}\right)$ to the total response strength of the RC frame retrofitted with the CFT-MF system $\left[\mathrm{V}_{\mathrm{T}}\right]$.

These results indicate that the CFT-MF system is an effective seismic retrofitting measure to significantly enhance the strength of RC structures. This superior seismic retrofitting method by strength increase is considered to efficiently increase the strength of middle- and low-rise RC structures with non-seismic details, and especially those with poor ductility.

\section{Conclusions}

The present study proposes a new seismic retrofitting method using a concrete-filled tube modular frame (CFT-MF) system, which is a novel technique to overcome and improve the limitations of existing seismic strengthening methods. A full-scale two-story test structure modeled from existing domestic RC structures with non-seismic details was subjected to pseudo-dynamic testing. As a result, the effect of the CFT-MF system, when applied to existing RC structures, was examined and verified, especially as to its seismic retrofitting performance, i.e., restoring force characteristics, and seismic response control. In addition, based on the pseudo-dynamic testing results, a restoring force characteristics model was proposed to implement non-linear dynamic analysis of a structure retrofitted 
with the CFT-MF system (i.e., the test frame). Finally, based on the proposed restoring force characteristics, non-linear dynamic analysis was conducted, and the results were compared with those obtained by the pseudo-dynamic tests. The major findings of the present study are as follows.

(1) The pseudo-dynamic test results of the test frame with no reinforcement applied showed that the maximum seismic response displacement was $58.7 \mathrm{~mm}$ (strength: $250.5 \mathrm{kN}$ ) at around $3.4 \mathrm{~s}$ when the Hachinohe wave (EW) of $200 \mathrm{~cm} / \mathrm{s}^{2}$ was applied. This also coincided with shear failure. These results indicated that the test structure was prone to shear failure and exhibited low ultimate strength, structural characteristics commonly found in domestic RC structures with non-seismic details of the 1980s. It was also found that such structures with non-seismic details may be subject to large-scale seismic damage when an earthquake with a magnitude of $200 \mathrm{~cm} / \mathrm{s}^{2}$ occurs. These data are considered important evidence to demonstrate the necessity of applying seismic retrofitting to such buildings.

(2) In the test frame retrofitted with the CFT-MF system, the maximum seismic response displacement was $11.0 \mathrm{~mm}$ (strength: $432.2 \mathrm{kN}$ ) when the Hachinohe wave (EW) of $200 \mathrm{~cm} / \mathrm{s}^{2}$ was applied. Only fine flexural cracks occurred, and the degree of overall structural damage was estimated to be insignificant. At $300 \mathrm{~cm} / \mathrm{s}^{2}$, the maximum seismic response displacement was $22.4 \mathrm{~mm}$ (strength: $613.3 \mathrm{kN}$ ). The initial flexural cracks increased in number, and small shear cracks occurred compared to when the input seismic acceleration was $200 \mathrm{~cm} / \mathrm{s}^{2}$. The degree of seismic damage was evaluated to be small. When the input seismic acceleration was $400 \mathrm{~cm} / \mathrm{s}^{2}$, i.e., when a large-scale earthquake was assumed, the maximum seismic response displacement was $39.5 \mathrm{~mm}$ (strength: $773.9 \mathrm{kN}$ ). Flexural and shear cracks increased in width, and the degree of overall structural damage was estimated to be moderate.

(3) The test frame retrofitted with the CFT-MF system exhibited seismic response strength about 1.72 times higher than the reference test frame when the same seismic acceleration was applied at $200 \mathrm{~cm} / \mathrm{s}^{2}$. The difference was even larger when the seismic acceleration was higher: about 2.45 times at $300 \mathrm{~cm} / \mathrm{s} 2$ and about 3.09 times at $400 \mathrm{~cm} / \mathrm{s}^{2}$. The test frame retrofitted with the CFT-MF system also exhibited smaller seismic response displacements than the reference test frame. The difference was about 0.19 times at $200 \mathrm{~cm} / \mathrm{s}^{2}$, about 0.38 times at $300 \mathrm{~cm} / \mathrm{s}^{2}$, and 0.67 times at $400 \mathrm{~cm} / \mathrm{s}^{2}$. When the same seismic acceleration was applied at $200 \mathrm{~cm} / \mathrm{s}^{2}$, the seismic response displacement was about $81 \%$ lower in the test frame retrofitted with the CFTMF system. These results indicated that the CFT-MF system was able to effectively enhance the ability of the test frame to absorb the applied seismic energy, verifying the effectiveness of the proposed seismic retrofitting method.

(4) The non-linear dynamic analysis and pseudo-dynamic testing methods, conducted at input seismic ground motions of 200,300 , and $400 \mathrm{~cm} / \mathrm{s}^{2}$, showed similar results. The deviation was about $10 \%$ or less on average. These results confirmed that the non-linear dynamic analysis model and methodology developed in the present study were able to effectively simulate the seismic behavior of the CFT-MF system and $\mathrm{RC}$ frames retrofitted with the system. This led to the conclusion that the seismic retrofitting performance of the CFT-MF system developed in the present study could be effectively evaluated via non-linear dynamic analysis based on the established analytical models and methods.

(5) This CFT-MF seismic retrofitting method makes the most of the advantages of both concrete and steel pipes, thereby significantly improving constructability and increasing integration between the existing structure and the reinforcement joints. This method falls into the category of typical seismic retrofitting methods that focus on increasing strength, in which the required amount of seismic reinforcement can be easily estimated. Therefore, the method provides a suitable solution to improving the strength of middle- and low-rise RC structures with non-seismic details that are prone 
to shear failure. The validity of the method was verified through pseudo-dynamic testing and non-linear dynamic analysis.

(6) To commercialize the Concrete-filled Tube Modular Frame (CFT-MF) going forward, a method to estimate the required amount of seismic reinforcement, along with seismic reinforcement design methods, needs to be proposed. Furthermore, the practicality of the CFT-MF seismic retrofitting method needs to be thoroughly assessed by conducting non-linear dynamic analysis of RC structures with non-seismic details retrofitted with the CFT-MF system.

Author Contributions: All authors have contributed to the development of the research and the elaboration of this article. Particularly, J.-S.K. contributed to the methodology, the experimental research and conceptualization; J.-S.J. and D.-K.J. contributed to the methodology, the experimental research and the dynamic analysis; E.-Y.K. contributed to the methodology and the experimental research; K.-S.L. contributed to the methodology and the experimental research, and edited the manuscript. All authors have read and agreed to the published version of the manuscript.

Funding: This research received no external funding.

Institutional Review Board Statement: Not applicable.

Informed Consent Statement: Not applicable.

Data Availability Statement: All datasets are available from the corresponding author on reasonable request.

Acknowledgments: This research was supported by a grant (2020-MOIS31-012) from the Fundamental Technology Development program for Extreme Disaster Response, funded by the Ministry of Interior and Safety, and a grant (21CTAP-C153033-03) from the Korea Agency for Infrastructure Technology Advancement Grant funded by the Ministry of Land, Infrastructure, and Transport Affairs of the Korean government.

Conflicts of Interest: The authors declare no competing interests.

\section{References}

1. Kobayashi, T.; Zen, K.; Yasufuku, N.; Nagase, H.; Chen, G.; Kasama, K.; Hirooka, A.; Wada, H.; Onoyama, Y.; Uchida, H. Damage to Residential Retaining Walls at the Genkai-Jima Island Induced by the 2005 Fukuoka-Ken Seiho-Oki Earthquake. Soil Found. 2006, 46, 793-804. [CrossRef]

2. Miyamoto, H.K.; Gilani, A.S.; Wada, A. Reconnaissance report of the 2008 Sichuan earthquake, damage survey of buildings and retrofit options. In Proceedings of the 14th World Conference on Earthquake Engineering, Beijing, China, 12-17 October 2008.

3. Sarrafzadeh, M.; Elwood, K.J.; Dhakal, R.P.; Ferner, H.; Pettinga, D.; Stannard, M.; Maeda, M.; Nakano, Y.; Mukai, T.; Koike, T. Performance of reinforced concrete buildings in the 2016 Kumamoto Earthquakes and seismic design in Japan. Bull. New Zealand Soc. Earthq. Eng. 2017, 50, 394-435. [CrossRef]

4. Architectural Institute of Korea (AIK). Site Inspection and Damage Investigation of Buildings by Earthquakes in Gyoungju and Pohang, Seoul, Korea. J. Korea Concr. Inst. 2018, 3, 1-47.

5. Abou-Elfath, H.; Ghobarah, A. Behavior of reinforced concrete frames rehabilitated with concentric steel bracing. Can. J. Civ. Eng. 2000, 27, 433-444. [CrossRef]

6. Ariyaratana, C.; Fahnestock, L.A. Evaluation of buckling-restrained braced frame seismic performance considering reserve strength. Eng. Struct. 2011, 33, 77-89. [CrossRef]

7. Badoux, M.; Jirsa, O. Steel bracing of RC frames for seismic retrofitting. J. Struct. Eng. ASCE 1990, 116, 55-74. [CrossRef]

8. Celik, O.C.; Bruneau, M. Seismic behavior of bidirectional-resistant ductile end diaphragms with buckling restrained braces in straight steel bridges. Eng. Struct. 2009, 31, 380-393. [CrossRef]

9. Ghobarah, A.; Abou-Elfath, H. Rehabilitation of a reinforced concrete frames using eccentric steel bracing. Eng. Struct. 2001, 23, 745-755. [CrossRef]

10. Lee, K.S. An experimental study on non-compression X-bracing systems using carbon fiber cable for seismic strengthening of RC buildings. Polymers 2015, 7, 1716-1731. [CrossRef]

11. Maheri, M.R.; Kousari, R.; Razazan, M. Pushover tests on steel X-braced and knee-braced RC frames. Eng. Struct. 2003, 25, 1697-1705. [CrossRef]

12. Ju, M.; Lee, K.S.; Sim, J.; Kwon, H. Non-compression cross-bracing system using carbon fiber anchors for seismic strengthening of RC structures. Mag. Concr. Res. 2014, 66, 159-174. [CrossRef]

13. Nateghi-Alahi, F. Seismic strengthening of eight-storey RC apartment building using steel braces. Eng. Struct. 1995, 17, 455-461. [CrossRef] 
14. Onat, O.; Correia, A.A.; Lourenço, P.B.; Koçak, A. Assessment of the combined in-plane and out-of-plane behavior of brick infill walls within reinforced concrete frames under seismic loading. Earthq. Eng. Struct. Dyn. 2018, 47, 2821-2839. [CrossRef]

15. Sarno, L.; Elnashai, A.S. Bracing systems for seismic retrofitting of steel frames. J. Constr. Steel Res. 2009, 65, 452-465. [CrossRef]

16. Smith, S.T.; Kim, S.J. Shear strength and behavior of FRP spike anchors in FRP-to-concrete joint assemblies. In Proceedings of the Fifth International Conference on Advanced Composite Materials in Bridges and Structures (ACMBS-V), Winnipeg, MB, Canada, 22-24 September 2008; ISBN 978-0-9736430-7-7.

17. Sugano, S. Seismic strengthening of existing reinforced concrete buildings in Japan. Bull. N. Z. Natl. Soc. Earthq. Eng. 1981, 14, 209-222. [CrossRef]

18. Pankaj, M.; Singh, S.B. Out-of-plane response of ECC-strengthened masonry walls. J. Struct. Integr. Maint. 2020, 5, 18-30.

19. Corey, T.G. Multi-performance retrofits to commercial buildings in seismic zones. J. Struct. Integr. Maint. 2017, 2, 133-142.

20. Hwang, J.S.; Lee, K.S. Seismic Strengthening Effects Based on Pseudodynamic Testing of a Reinforced Concrete Building Retrofitted with a Wire-Woven Bulk Kagome Truss Damper. Shock Vib. 2016, 2016, 1-17. [CrossRef]

21. Kunisue, A.; Koshika, N.; Kurokawa, Y.; Suzuki, N.; Agami, J.; Sakamoto, M. Retrofitting method of existing reinforced concrete buildings using elasto-plastic steel dampers. In Proceedings of the 12th World Conference on Earthquake Engineering, Auckland, New Zeland, 30 January-4 February 2000.

22. Marko, J.; Thambiratnam, D.; Perera, N. Influence of damping systems on building structures subject to seismic effects. Eng. Struct. 2004, 26, 1939-1956. [CrossRef]

23. Sarranya, B.; Aparna, D.G. Optimal design of nonlinear TMD with Bingham-type damping for base-excited structures. J. Struct. Integr. Maint. 2020, 5, 211-222.

24. Oliveto, G.; Caliò, I.; Marletta, M. Retrofitting of Reinforced Concrete Buildings Not Designed to Withstand Seismic Action: A Case Study Using Base Isolation. In Proceedings of the 13th World Conference on Earthquake Engineering, Vancouver, BC, Canada, 1-6 August 2004. Paper No. 954.

25. Lee, K.S.; Jung, J.S. A Seismic Capacity of R/C Building Damaged by the 2016 Gyeongju Earthquake Based on the Non-linear Dynamic Analysis. J. Korea Inst. Struct. Maint. Insp. 2018, 22, 137-146.

26. Lee, K.S.; Choi, H.; Yi, W.H. Earthquake Damage Ratio Estimation and Seismic Capacity Evaluation of Existing Reinforced Concrete Buildings in Korea. J. Archit. Inst. Korea 2002, 18, 11-20. [CrossRef]

27. Lee, K.S.; Wi, J.D.; Kim, Y.I.; Lee, H.H. Seismic Safety Evaluation of Korean R/C School Buildings Built in the 1980s. J. Korea Inst. Struct. Maint. Insp. 2009, 13, 1-11.

28. Federal Emergency Management Agency (FEMA). FEMA 356: Prestandard and Commentary for Seismic Rehabilitation of Buildings; FEMA: Washington, DC, USA, 2000; p. 450.

29. Japan Building Disaster Prevention Association (JBDPA). Guideline for Seismic Strengthening of Existing Reinforced Concrete Buildings; JBDPA: Tokyo, Japan, 2017; p. 197.

30. Seismic Strengthening Research Group (SSRG). Seismic Strengthening of RC Buildings; Ohmsha Press: Tokyo, Japan, 2008; 230p.

31. Takanashi, K.; Udagawa, K.; Tanaka, H. Pseudo-dynamic tests on a 2-storey steel frame by a computer-load test apparatus hybrid system. In Proceedings of the 7th World Conference on Earthquake Engineering, Istanbul, Turkey, 8-13 September 1980; Volume 7, pp. 225-232.

32. Tokyo Soki Kenkyujo Company (TSKC), 2020, Tokyo, Japan. Available online: https://www.tml.jp/e/ (accessed on 10 April 2021).

33. MTS Pseudodynamic Testing for 793 Controllers; MTS Systems Corporation: Eden Prairie, MI, USA, 2002.

34. Hilber, H.M.; Hughes, T.J.; Taylor, R.L. Improved numerical dissipation for time integration algorithms in structural dynamics. Earthq. Eng. Struct. Dyn. 1977, 5, 283-292. [CrossRef]

35. Lee, K.S. Seismic capacity requirements for low-rise reinforced concrete buildings controlled by both shear and flexure. J. Adv. Concr. Technol. 2010, 8, 75-91. [CrossRef]

36. Korean Design Standard 41 (KDS 41) Korean Design Standard 41; Architectural Institute of Korea: Seoul, Korea, 2019.

37. KS B 0801. Test Pieces for Tension Test for Metallic Materials; Korean Industrial Standards: Eumseong-gun, Korea. Available online: https: / / standard.go.kr (accessed on 12 April 2021).

38. Jung, H.C.; Jung, J.S.; Lee, K.S. Seismic performance evaluation of internal steel frame connection method for seismic strengthening by cycling load test and nonlinear analysis. J. Korea Con. Inst. 2019, 31, 79-88. [CrossRef]

39. Japan Building Disaster Prevention Association (JBDPA). Standard for Damage Level Classification; JBDPA: Tokyo, Japan, 2015; p. 360 .

40. Maeda, M.; Nakano, Y.; Lee, K.S. Post-Earthquake Damage Evaluation for R/C Buildings Based on Residual Seismic Capacity. In Proceedings of the 13th World Conference on Earthquake Engineering, Vancouver, BC, Canada, 1-6 August 2004; p. 1179.

41. Architectural Institute of Japan (AIJ). Standard for Structural Calculation of Reinforced Concrete Structures; AIJ: Tokyo, Japan, 2010; p. 952.

42. Li, K.N. Canny: A 3-dimensional Nonlinear Dynamic Structural Analysis Computer Program (User Manual); CANNY Structural Analysis Company: Vancouver, BC, Canada, 2009. 